\title{
miR-543 acts as a novel oncogene in oral squamous cell carcinoma by targeting CYP3A5
}

\author{
LIPING WANG ${ }^{*}$, WEIHONG CHEN ${ }^{*}$, JUN ZHA ${ }^{*}$, YONGYONG YAN, YONGXIANG WEI, \\ XILI CHEN, XINXIN ZHU and LINHU GE \\ Key Laboratory of Oral Medicine, Guangzhou Institute of Oral Disease, \\ Stomatology Hospital of Guangzhou Medical University, Guangzhou, Guangdong 510140, P.R. China
}

Received May 9, 2018; Accepted July 3, 2019

DOI: $10.3892 /$ or.2019.7230

\begin{abstract}
MicroRNAs (miRNAs/miRs) are small non-coding RNAs that can act as oncogenes or tumor-suppressor genes in human cancer. Previous studies have revealed that abnormal expression of miRNAs is closely associated with tumor cell cycle, differentiation, growth and apoptosis. miR-543 is expressed abnormally in a wide variety of cancers and has been associated with cellular proliferation, apoptosis, and invasion; however, the effect of miR-543 remains unknown in oral squamous cell carcinoma (OSCC). In the present study, the expression level of miR-543 in OSCC cell lines and tissues was investigated by RT-qPCR. A series of experiments was then performed to elucidate the functions of miR-543 in OSCC, such as CCK-8 assay, colony formation assay, flow cytometry, cell cycle distribution assay and cell apoptosis assay and Transwell assay. miR-543 expression was significantly upregulated in tumors from patients with OSCC and in OSCC cell lines. Overexpression of miR-543 promoted the proliferation, invasion and migration of OSCC cell lines, and inhibited cell apoptosis. In addition, the present study identified cytochrome P450 family 3 subfamily A member 5 (CYP3A5) as a direct target of miR-543 using software analysis and dual-luciferase reporter assays. In conclusion, the results of the present study suggest that miR-543 acts as a tumor promoter and serves a vital role in OSCC proliferation and invasion. These results confirm that miR-543 may serve as a potential novel target for the treatment of OSCC.
\end{abstract}

Correspondence to: Professor Linhu Ge, Key Laboratory of Oral Medicine, Guangzhou Institute of Oral Disease, Stomatology Hospital of Guangzhou Medical University, 39 Huangsha Avenue, Liwan, Guangzhou, Guangdong 510140, P.R. China

E-mail: gelinhu@yeah.net

*Contributed equally

Key words: microRNA-543, cytochrome P450 family 3 subfamily A member 5, CYP3A5, proliferation, invasion, migration, oral squamous cell carcinoma

\section{Introduction}

Oral squamous cell carcinoma (OSCC) is one of the most frequently diagnosed types of cancer worldwide, with more than 500,000 new patients diagnosed annually in the world (1). OSCC accounts for the highest incidence of malignant tumors in the head and neck, and patients are often prone to tumor invasion and metastasis. In addition, OSCC is the sixth most common type of cancer worldwide, accounting for $\sim 5 \%$ of all malignant tumors (2). Although there are currently many treatments available for OSCC, including surgical resection, radiotherapy and chemotherapy, the patient prognosis remains relatively poor. These treatments also tend to present serious side effects, for example, postoperative recurrence, postoperative hematoma, tooth decay, radiation osteonecrosis, gastrointestinal reactions and systemic diseases after chemotherapy. Therefore, elucidation of the molecular mechanism underlying oral cancer is required in order to identify novel therapeutic targets and diagnostic markers. An increasing number of studies have revealed that microRNAs (miRNAs/miRs) are closely associated with the occurrence and development of OSCC (3-5).

miRNAs are a class of small molecular non-coding RNAs, 19-24 nucleotides in length, which act through targeting mRNAs. Since the discovery of miRNAs, more than 2,500 human miRNAs have been reported (6). The abnormal expression of miRNAs, when comparing normal and cancerous tissues, is closely associated with biological processes in tumors, including the cell cycle, proliferation, differentiation, growth and apoptosis (7). miRNAs can act as oncogenes or tumor-suppressor genes (8-11). However, greater understanding of the involvement of miRNAs in the development and progression of OSCC is required. miR-543, a member of the miRNA family, has become a key item of interest in recent years. It has been revealed to have an abnormal expression and serve an important role in a variety of different types of cancers, including lung cancer (12), gastric cancer (13), hepatocellular carcinoma (14), breast cancer (15), colorectal cancer (16) and ovarian cancer (17), to name a few. Nevertheless, the role of miR-543 in OSCC remains unknown.

Previous studies have demonstrated that cytochrome P450 is involved in the treatment of tumors, such as hepatocellular carcinoma, prostate cancer and bladder cancer, but also has 
a strong correlation with the occurrence and development of tumors (18-20). Cytochrome P450 family 3 subfamily A member 5 (CYP3A5) is a member of the cytochrome P450 superfamily of enzymes that are involved in the metabolic processes of endogenous molecules including drugs, exogenous carcinogens and steroids (21). Early studies have reported that the abnormal expression of CYP3A5 may be associated with the progression of $\mathrm{HCC}$ and may serve as a target for the treatment of hepatitis C-associated HCC as well as a marker (22). However, the associations between CYP3A5 and OSCC have not been reported. In the present study, it was demonstrated that CYP3A5 exhibits low expression in OSCC tissues and cell lines, may serve as a direct target gene for miR-543 and promotes the growth of OSCC cells.

\section{Materials and methods}

Cell culture. Three oral cancer cell lines (SCC9, SCC25 and CAL27) and one normal human oral keratinocyte (HOK) cell line were used in the present study. SCC9, SCC25, and CAL27 cells are human tongue squamous cell carcinoma cell lines, of which SCC9 was a gift from Wuhan University (Hubei, China), SCC25 was purchased from the Biological Resources Center of the ATCC (The Global Bioresource Center, Manassas, VA, USA), and CAL27 was obtained from the Center Laboratory of Stomatology Hospital of Guangzhou Medical University (Guangdong, China). HOK cells are normal human oral keratinocyte strains (23) which were purchased from the ScienCell Research Laboratories, Inc. (no. 2610; San Diego, CA, USA). The cancer cell lines were grown in $100 \%$ Dulbecco's modified Eagle's medium (DMEM)/F12 medium containing $10 \%$ fetal bovine serum (FBS; Gibco; Thermo Fisher Scientific, Inc., Waltham, MA, USA). The HOK cells were maintained in $100 \%$ DMEM medium containing $10 \% \mathrm{FBS}$. All cells were cultured at $37^{\circ} \mathrm{C}$ in a humidified atmosphere with $5 \% \mathrm{CO}_{2}$.

Clinical specimens. The present study was approved by the Research Ethics Committee of the Stomatology Hospital of Guangzhou Medical University (Guangdong, China). Written informed consent was obtained from all of the patients recruited. All of the oral carcinoma tissues and adjacent normal tissues were collected from patients who had undergone surgery at the Stomatology Hospital of Guangzhou Medical University from January 2016 to June 2017. A total of 20 patients, including 9 males and 11 females were recruited. Twelve individuals were 50 years of age or older, 8 individuals were younger than 50 years. The age range was $35-70$ years old, with an average age of 50.4 \pm 7.56 years. The inclusion criteria for patients with OSCC were: i) histological confirmation of OSCC; and ii) no prior history of any other type of cancer.

Transfection of miR-543 mimic and inhibitor. Chemically modified miR-543 mimics, miRNA mimic negative control (NC), miR-543 inhibitor and miRNA inhibitor NC, were transfected into cells using GenMute transfection reagent (SignaGen Laboratories, Rockville, MD, USA) according to the manufacturer's protocol (24), in order to determine the levels of upregulated or downregulated expression in various genes, such as CYP3A5, CYB5R4, BIRC6, NR3C1 and
PRKG1, and also to observe the effect of the OSCC cell line phenotype. The sequences are listed in Tables I and II.

Transfection of CYP3A5 small interfering (si)RNA. CYP3A5 siRNA and NC were transfected into SCC9 cells using GenMute transfection reagent (SignaGen Laboratories) according to the manufacturer's protocol, in order to observe the effect of the SCC9 cell phenotype. The sequences are listed in Table I.

Cell proliferation assays. Cell proliferation was measured using a Cell Counting Kit-8 (CCK-8; Dojindo Laboratories, Kumamoto, Japan). A total of $\sim 5 \times 10^{3}$ OSCC cells were plated into 96-well plates, and $10 \mu \mathrm{l}$ of the CCK-8 solution was added into each well $0,1,2$ and 3 days following cell plating. The 96-well plates were incubated for $4 \mathrm{~h}$ at $37^{\circ} \mathrm{C}$, and the absorbancies at each time-point were measured at $450 \mathrm{~nm}$ using a microplate reader. Each experiment was repeated three times.

Colony formation assay. The clonogenicity of a single cell was detected by a colony formation assay. The different groups of cells were added to each well of 6-well plates and cultured in DMEM/F12 medium containing 10\% FBS for 10 days. SCC9 and CAL27 cells were collected using $0.25 \%$ trypsin and the concentration was adjusted to 600 cells/pPetri dish; SCC25 cells were adjusted to a concentration to 300 cells/Petri dish, which was diluted with $2 \mathrm{ml}$ of preheated culture media prior to culture at $5 \% \mathrm{CO}_{2}$ and $37^{\circ} \mathrm{C}$ for 10 days. Colony formation was terminated when the colony was visible to the naked eye. Once visible, cells were washed twice with phosphate-buffered saline (PBS), and then $4 \%$ paraformaldehyde was added for $30 \mathrm{~min}$ to fix the cells prior to staining with crystal violet for $30 \mathrm{~min}$. Following this, the number of colonies was counted and the colony formation rate was calculated as follows: Colony formation rate $=($ Number of colonies $/$ Inoculated cell number) $\mathrm{x} 100 \%$.

Cell cycle analysis. The BD propidium iodide (PI) Cell Cycle Detection Kit (BD Biosciences, San Jose, CA, USA) was used to detect the cell cycle in SCC9, SCC25 and CAL27 cells according to the manufacturer's instructions. The cells were digested with trypsin and collected after centrifugation at $845 \mathrm{x}$ g. Following collection, the cells were washed twice with cold PBS. Cells were harvested, fixed with $70 \%$ ice-cold ethanol at $4^{\circ} \mathrm{C}$ overnight and then re-suspended. The cells were then collected via centrifugation at $2535 \mathrm{x} \mathrm{g}$, washed twice with PBS, centrifuged again, and finally stained with PI at room temperature for $30 \mathrm{~min}$ in the dark. Cell cycle assays were performed using a flow cytometer (BD Biosciences). The results were analyzed using Modfit LT software (Verity Software House, Inc., Topsham, ME, USA). Each experiment was repeated three times.

Apoptosis assays. A BD Annexin V-Fluorescein Isothiocyanate (FITC) Apoptosis Detection Kit (BD Biosciences) was used to detect the levels of apoptosis in SCC9, SCC25 and CAL27 cells according to the manufacturer's instructions. The cells were digested with trypsin and collected after centrifugation at $845 \mathrm{x}$ g. Following collection, the cells were washed twice with cold PBS. The cell pellet $\left(\sim 1-5 \times 10^{5}\right.$ cells) was re-suspended 
Table I. Sequences of the miR-543 mimic or inhibitor or NC and CYP3A5 siRNA or siRNA NC.

Name

Sequence (5' to $\left.3^{\prime}\right)$

miR-543 mimic

miRNA mimic NC

miR-543 inhibitor

miRNA inhibitor NC

CYP3A5 SiRNA

siRNA NC

\author{
AAACAUUCGCGGUGCACUUCUU \\ UUUGUACUACACAAAAGUACUG \\ UACUUAAUGAGAAGUUGCCCGUGUUUUUUUCGCUUUAUUU \\ GUGACGAAACAUUCGCGGUGCACUUCUUUUUCAGUAU \\ mirVana $^{\mathrm{TM}}$ miRNA Inhibitor, Negative Control \#1, \\ hermoFisher Scientific, cat. no. 4464076 \\ TCTGTCTTCACAAATCGAA \\ RiboBio, cat. no. siN05815122147
}

CYP3A5, cytochrome P450 family 3 subfamily A member 5; NC, negative control; siRNA, small interfering RNA.

in $500 \mu \mathrm{l}$ Binding Buffer. Then, $5 \mu \mathrm{l}$ Annexin V-FITC and $5 \mu \mathrm{l}$ PI were added and mixed at room temperature (protected from light) for $20 \mathrm{~min}$. Within $1 \mathrm{~h}$, the cells were detected by flow cytometry (BD Biosciences). The green fluorescence of Annexin V-FITC was detected through a FITC channel (FL1); and PI red fluorescence was detected by a PI channel (FL2 or FL3). Cells that did not undergo apoptosis-inducing treatment were used as the controls for fluorescence compensation setting adjustments. Each experiment was repeated three times.

Invasion and migration assays. Transwell migration and invasion assays were performed with an $8-\mu \mathrm{m}$ pore size transwell chamber (Corning Inc., Corning, NY, USA). For invasion assays, membranes were coated with $50 \mu \mathrm{l}$ of growth factor-reduced Matrigel (BD Biosciences). Serum-starved cells $(80,000$ cells/well) were plated into the upper chamber in $200 \mu \mathrm{l}$ of serum-free DMEM/F12. As the chemoattractant, $500 \mu \mathrm{l}$ of complete medium was used in the lower chamber. For migration and invasion assays, the cells were incubated for $24 \mathrm{~h}$. Assessment of migration and invasion was performed by gently removing the cells in the interior part of the insert with a cotton swab. Cells on the bottom of the membrane were fixed with $4 \%$ paraformaldehyde for $20 \mathrm{~min}$ and stained with $1 \%$ crystal violet solution. The excess dye was washed away and then dried for $20 \mathrm{~min}$. Fluorescence microscopy was performed and photographs were captured while counting cells using Image Tool (Leica DM4000; Leica Mocrosystems, Tokyo, Japan). In Transwell migration and invasion assays, $100 \mathrm{nM}$ miRNA inhibitor or $75 \mathrm{nM}$ miRNA mimic or $100 \mathrm{nM}$ CYP3A5 siRNA were transfected $48 \mathrm{~h}$ prior to cell seeding on the upper chamber. Each experiment was repeated three times.

Reverse transcription-quantitative polymerase chain reaction (RT-qPCR). Total RNAs were extracted using TRIzol reagent (Thermo Fisher Scientific, Inc.) according to the manufacturer's protocol and then quantified using NanoDrop 2000 (Thermo Fisher Scientific, Inc.). The PrimeScript ${ }^{\mathrm{TM}}$ RT Reagent Kit (Takara Biotechnology Co., Ltd., Dalian, China) was utilized for RT-PCR. microRNAs were extracted using RNAiso reagent (Takara Biotechnology Co., Ltd.) and then quantified using NanoDrop 2000 (Thermo Fisher Scientific, Inc.). RT-qPCR was subsequently performed according to
Table II. Primer sequences of the genes used for this study.

\begin{tabular}{|c|c|}
\hline Gene & Primer sequence ( $5^{\prime}$ to $\left.3^{\prime}\right)$ \\
\hline hsa-miR-543 & ACATTCGCGGTGCACTTCTT \\
\hline \multirow[t]{2}{*}{ CYP3A5 } & F: TGTTATTCTGTCTTCACAAATCGAA \\
\hline & R: CCTCAAGTTTCTCACCAATACATCT \\
\hline \multirow[t]{2}{*}{$C Y B 5 R 4$} & F: TTGACCCAACGATGAACCTGA \\
\hline & R: AAGGATCTAACGGGATTAAAAGGC \\
\hline \multirow[t]{2}{*}{ BIRC6 } & F: GTGAACTGGGATAATCTTGAGGAAA \\
\hline & R: GCTGTGATGAGGAGCGACTTG \\
\hline \multirow[t]{2}{*}{$B C L 6 B$} & F: TCCGCAGATTGAGCAGTGGTA \\
\hline & R: CAGAACTGTGAGGCTGTGGCA \\
\hline \multirow[t]{2}{*}{$N R 3 C 1$} & F: GTTTCTGCGTCTTCACCCTCACT \\
\hline & R: CATTTCCCATCACTTTTGTTTCTGT \\
\hline \multirow[t]{2}{*}{ PRKG 1} & F: AGGATGAGATTTTCTGGCTTG \\
\hline & R: ATTCTCAGGGATAGAGGTTCG \\
\hline \multirow[t]{2}{*}{ TNFSF 11} & F: TGATGAAAGGAGGAAGCA \\
\hline & R: GTAAGGAGGGGTTGGAGA \\
\hline \multirow[t]{2}{*}{ EIF1 } & F: TGTAACCATTTGGGGTCCGCTT \\
\hline & R: TTTGTAATCTTAGGGCTCTGGGCTT \\
\hline \multirow[t]{2}{*}{ ING1 } & F: CACCTCAACAAAGGCAGCAAT \\
\hline & R: GGACAAAGCCCTGGAGAAATC \\
\hline \multirow[t]{2}{*}{$G A D P H$} & F: AAGAAGGTGGTGAAGCAGG \\
\hline & R: GAAGGTGGAAGAGTGGGAGT \\
\hline \multirow[t]{2}{*}{ U6 } & F: GGAACGATACAGAGAAGATTAGC \\
\hline & R: TGGAACGCTTCACGAATTTGCG \\
\hline
\end{tabular}

F, forward; R, reverse. CYP $3 A 5$, cytochrome $\mathrm{P} 450$ family 3 subfamily A member 5; CYB5R4, cytochrome B5 reductase 4; BIRC6, baculoviral IAP repeat containing $6 ; B C L 6 B, B C L 6 \mathrm{~B}$ transcription repressor; $N R 3 C 1$, nuclear receptor subfamily 3 group $\mathrm{C}$ member 1 ; PRKG1, protein kinase CGMP-dependent 1; TNFSF 11, TNF superfamily member 11; EIF1, eukaryotic translation initiation factor 1 ; ING1, inhibitor of growth family member $1 ; G A D P H$, glyceraldehyde-3-phosphate dehydrogenase; U6, RNA, U6 small nuclear 1.

the SYBR ${ }^{\circledR}$ Premix Ex Taq II ${ }^{\text {TM }}$ kit instructions (Takara Biotechnology Co., Ltd.). The reaction conditions were as follows: $95^{\circ} \mathrm{C}$ for $30 \mathrm{sec}$; and $95^{\circ} \mathrm{C}$ for $5 \mathrm{sec}, 55^{\circ} \mathrm{C}$ for $30 \mathrm{sec}$ 
and $72^{\circ} \mathrm{C}$ for $30 \mathrm{sec}$ for 40 cycles. Primers for the target genes are listed in Table II. For each sample, gene expression was analyzed using the $2^{-\Delta \Delta \mathrm{Cq}}$ method (25). The results were normalized against an internal control (U6 RNA for miRNAs or GAPDH for mRNA). All experiments were repeated at least three times.

Western blotting. Cells were washed twice with ice-cold PBS and re-suspended in ice-cold radioimmunoprecipitation assay buffer containing $1 \mathrm{mmol} / \mathrm{l}$ phenylmethanesulfonyl fluoride and a cocktail of protease inhibitors (1:100 dilution; Beyotime, Institute of Biotechnology, Nantong, China). Samples were centrifuged at $10,140 \mathrm{xg}$ at $4^{\circ} \mathrm{C}$ for $15 \mathrm{~min}$. Supernatants were recovered and total protein concentration was quantified using a bicinchoninic acid protein assay kit (Beyotime, Institute of Biotechnology). Equal amounts of protein were loaded and separated on $10 \%$ SDS-PAGE and transferred to polyvinylidene fluoride membranes (PALL, Life Sciences, Port Washington, NY, USA). The amount of protein loaded per channel was $20 \mu \mathrm{g}$. Membranes were blocked for $2 \mathrm{~h}$ at room temperature with 5\% milk in PBS containing 0.05\% Tween-20 (PBST), and then incubated overnight with the following primary antibody (1:1,000; cat. no. ab108624) and anti- $\beta$-actin (1:5,000; cat. no. ab8227) (both from Abcam, Cambridge, UK). Membranes were then washed three times with PBST, incubated with secondary antibody anti-rabbit IgG H\&L (HRP) (1:4,000; cat. no. ab205718) (Abcam) for $2 \mathrm{~h}$, washed three times with PBST, and visualized using an Enhanced Chemiluminescence (ECL) system. $\beta$-actin served as the internal loading control. The protein bands were quantified by densitometry using QuantityOne software (Bio-Rad, Laboratories, Inc., Hercules, CA, USA), and the values are expressed relative to $\beta$-actin. Each experiment was repeated three times.

miRNA target gene prediction. The relationship between miRNAs and genes was predicted by miRNA target prediction software based on TargetScan (http://www.targetscan.org) and miRDB (http://www.mirdb.org/). Target genes associated with target score and growth or proliferation were screened and then verified in OSCC cell lines. Some of target genes are listed in Tables III and IV.

Correlation analysis (26). According to the expression levels of miR-543 and CYP3A5 in 20 pairs of OSCC tissues, the correlation of expression levels was analyzed, and the correlation equation was calculated statistically to obtain the linear regression relationship. First, we analyzed the expression level of miR-543 and CYP3A5 in 20 pairs of OSCC tissues by linear regression. The Enter regression method was used to obtain the linear regression equation and $\mathrm{R}$ value. Then we used the Enter method to verify the equation.

$m R N A$ profile data and miRNA survival analysis. The UALCAN (http://ualcan.path.uab.edu/) data from The Cancer Genome Atlas (TCGA), was then used to online analyze the gene CYP3A5 expression in head and neck squamous cell carcinoma (HNSC) (27). OncoLnc (http://www.oncolnc. org) was used as a tool for interactively exploring survival correlations (28). OncoLnc dataset contains survival data for 250 patients from HNSC cancer studies performed by TCGA.
Luciferase dual-reporter assays. 293T cells are most commonly used in dual luciferase reporter gene assays $(29,30)$. 293 T cells were obtained from the Center Laboratory of Stomatology Hospital of Guangzhou Medical University (Guangdong, China). 293T cells were co-transfected with the miR-543-expressing plasmid or control vector, the indicated firefly luciferase reporter plasmids and a Renilla luciferase plasmid with a ratio of 2:2:1 $(31,32)$. Lysates were collected 72 h post-transfection. Firefly and Renilla luciferase activities were measured using a Dual-Luciferase Reporter System (Promega Corporation, Madison, WI, USA). Detection value ratio=Renilla luciferase detection value/firefly luciferase detection value.

Immunohistochemistry (IHC). IHC staining of human OSCC tissues was performed on deparaffinized OSCC tissue sections using primary antibody against CYP3A5 (dilution, 1:100; cat. no. ab108624; Abcam) overnight at $4^{\circ} \mathrm{C}$. For the negative control for immunohistochemistry analysis, the primary antibody was replaced with normal IgG (dilution 1:100; cat. no. ab172730; Abcam) overnight at $4^{\circ} \mathrm{C}$. The slides were subsequently treated with biotinylated anti-rabbit secondary antibody anti-rabbit IgG H\&L (HRP) (dilution 1:4,000; cat. no. ab205718; Abcam) and counterstained with hematoxylin. Control experiments were performed using non-immune immunoglobulins as opposed to specific antibody. Immunostained images were captured using a digital camera; five images were captured at random.

Statistical analysis. SPSS 20.0 software (IBM Corp., Armonk, NY, USA) was used for statistical analysis, and the data are presented as the mean \pm standard error of the mean. Statistical analysis was performed using a paired t-test or one-way analysis of variance (ANOVA). The data of three or more groups were evaluated using analysis of variance and least significant difference (LSD) post hoc tests when the variance was normal. $\mathrm{P}<0.05$ was considered to indicate a statistically significant difference. All experiments were conducted at least three times.

\section{Results}

High expression of miR-543 in OSCC cell lines and human tissues. In order to investigate the potential mechanism of miR-543 in OSCC, the expression of miR-543 was detected by RT-qPCR in 20 pairs of OSCC tissues and adjacent non-tumor tissues obtained during clinical operations (Fig. 1A). The results of RT-qPCR demonstrated that miR-543 was significantly increased in cancerous tissues when compared with that noted in the adjacent non-tumor tissues (Fig. 1B; $\mathrm{P}<0.0001$ ). In order to further determine the role of miR-543 in OSCC, the gene expression levels of miR-543 in the OSCC cell lines SCC9, SCC25 and CAL27 were detected. When compared with human normal oral keratinocytes (HOK) cells, miR-543 exhibited a higher expression in SCC9, SCC25 and CAL27 cells (Fig. 1C).

miR-543 promotes the growth of OSCC cell lines in vitro. To investigate the mechanism of action underlying miR-543 in OSCC, the present study attempted to determine whether 

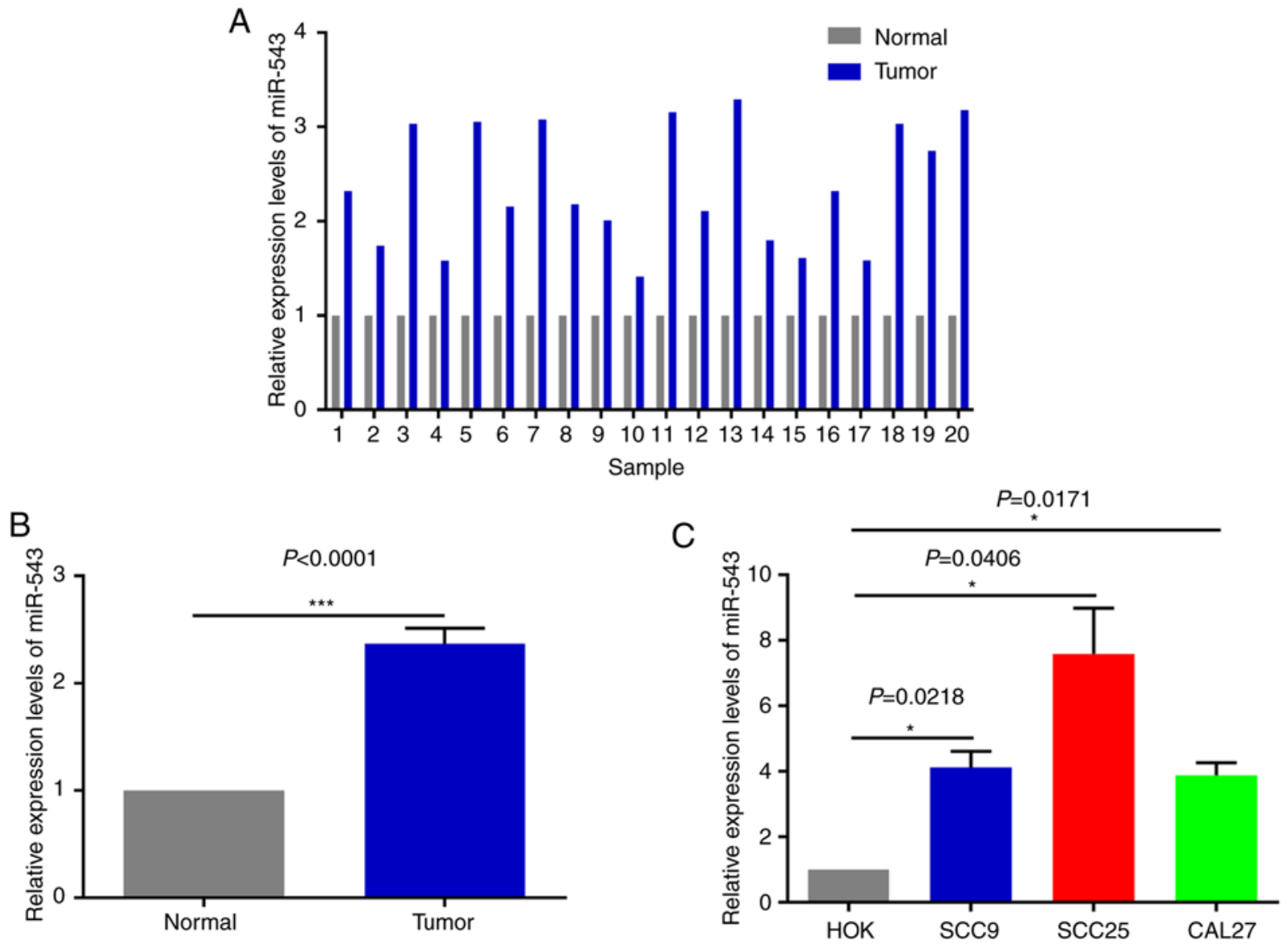

Figure 1. High expression of miR-543 in OSCC cell lines and human tissues. (A and B) Expression of miR-543 was detected in 20 paired clinical samples. Results of RT-qPCR revealed that miR-543 was increased in cancerous tissues when compared with that in adjacent non-tumor tissues. $\mathrm{<}<0.0001$, cancer tissues vs. adjacent non-tumor tissues. (C) RT-qPCR was performed to analyze the expression of miR-543, which was significantly increased in 3 OSCC cell lines, SCC9, SCC25 and CAL27, when compared with that noted in HOK cells. ${ }^{*} \mathrm{P}<0.05,{ }^{* * *} \mathrm{P}<0.001$. miR, microRNA; OSCC, oral squamous cell carcinoma; RT-qPCR, reverse transcription-quantitative polymerase chain reaction.
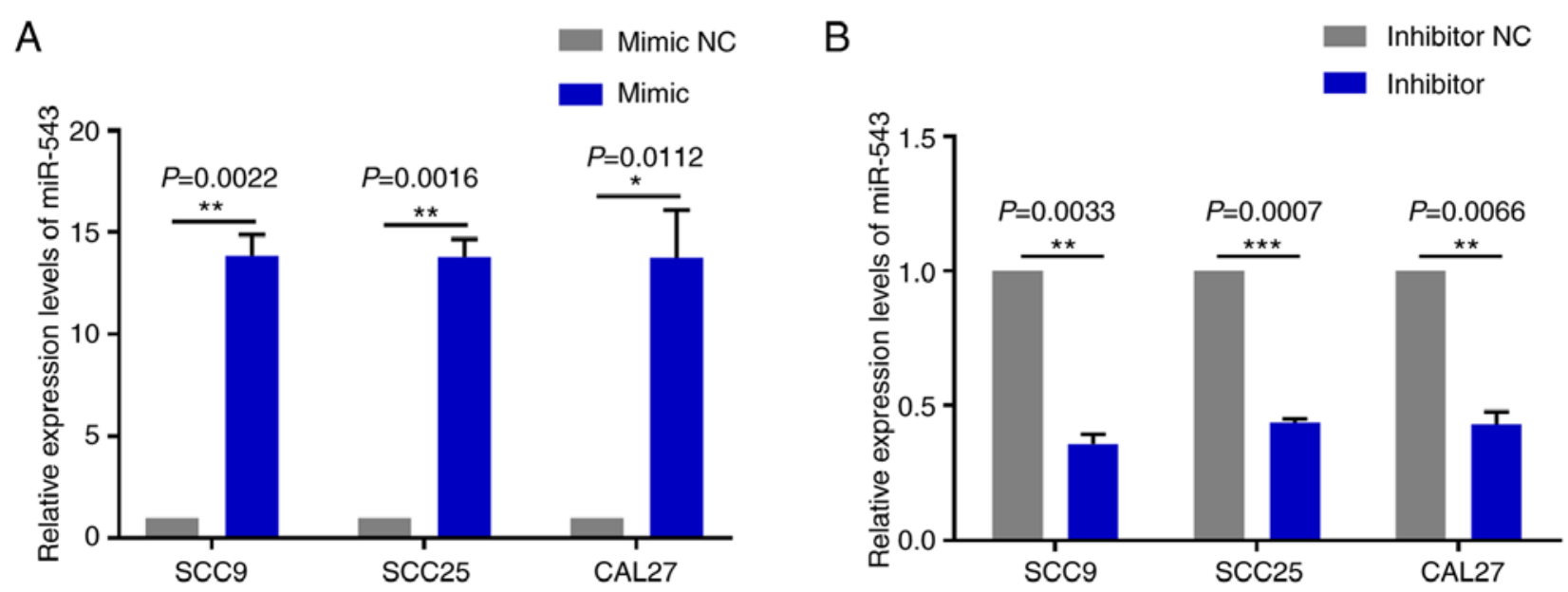

Figure 2. Transfection efficiency of miR-543 mimic and inhibitor. (A) miR-543 expression was significantly upregulated in the three OSCC cell lines following transfection with miR-543 mimic when compared with the mimic NC. (B) miR-543 expression was significantly downregulated in the three OSCC cell lines following transfection with the miR-543 inhibitor when compared with the inhibitor NC. The expression of miR-543 was normalized to U6 RNA. "P<0.05, ${ }^{* *} \mathrm{P}<0.01,{ }^{* * *} \mathrm{P}<0.001$. OSCC, oral squamous cell carcinoma; NC, negative control.

miR-543 affects OSCC cell line proliferation. SCC9, SCC25 and CAL27 cells were transfected with mimic NC, miR-543 mimic, inhibitor NC or miR-543 inhibitor; the results demonstrated a high transfection efficiency (Fig. 2A and B).
The CCK- 8 assay results indicated that when compared with the NC group, overexpression of miR-543 significantly increased the proliferation of OSCC cell lines (Fig. 3A). By contrast, miR-543 inhibitor significantly decreased the 
A

Scc9

SCC25

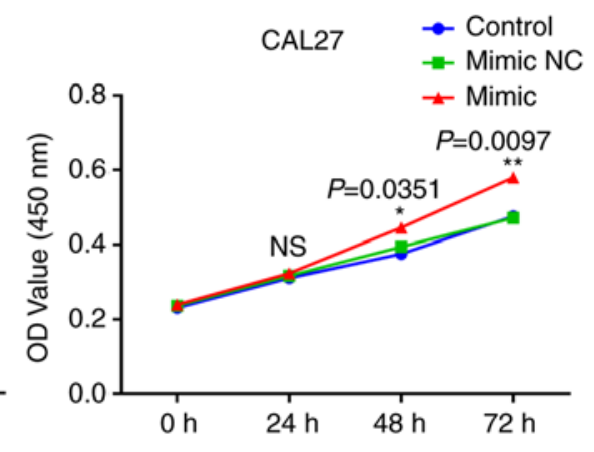

B
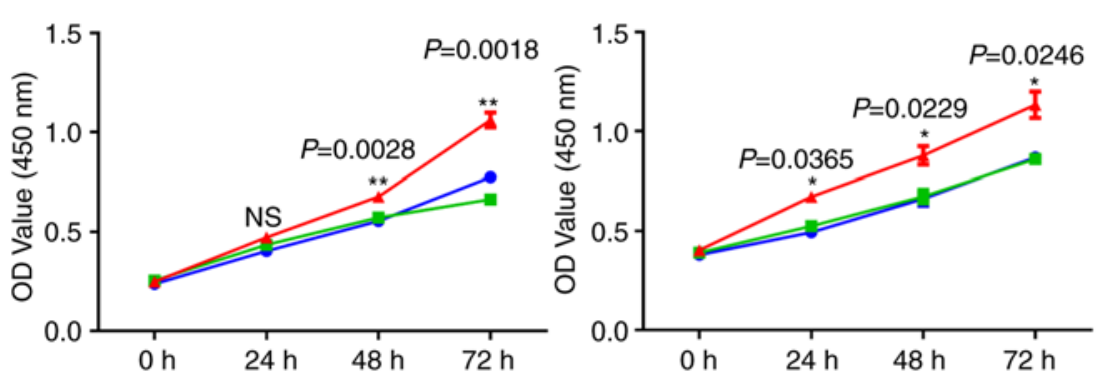

scc9

$\operatorname{scc} 25$
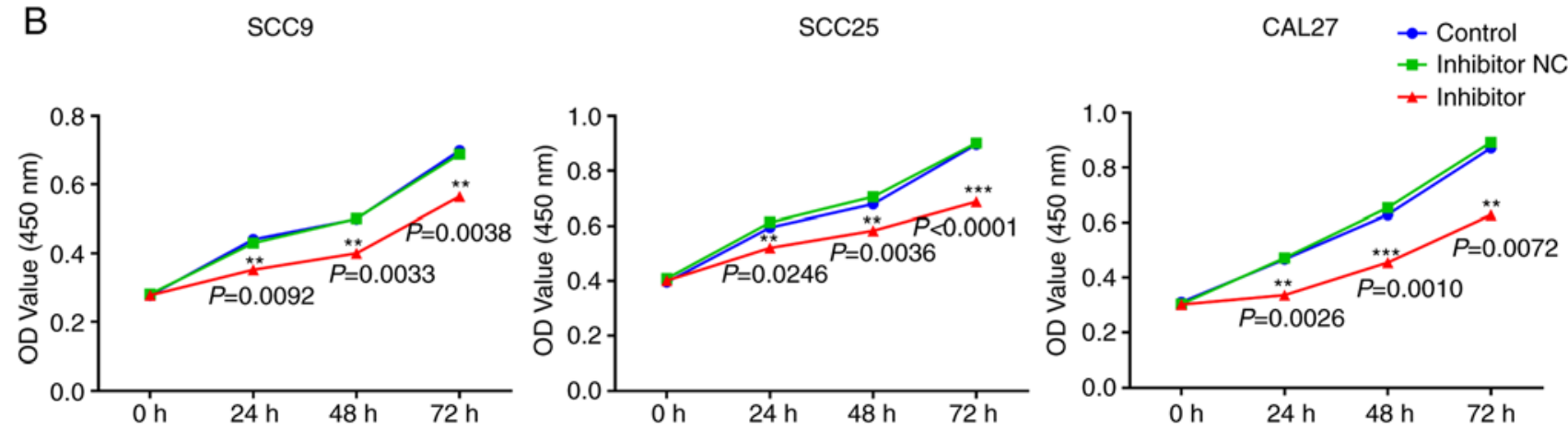

C

C $\quad \operatorname{scc} 9$
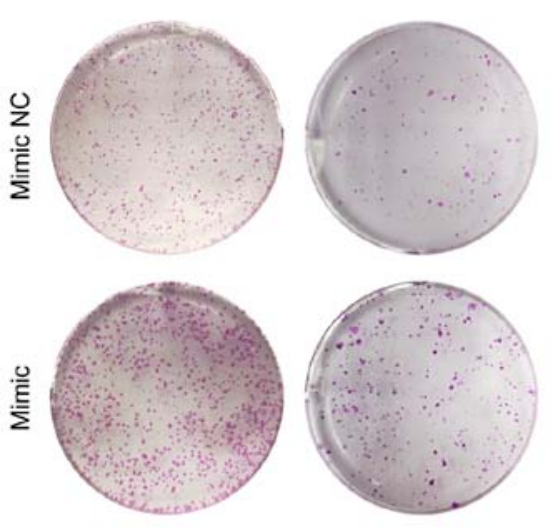

D
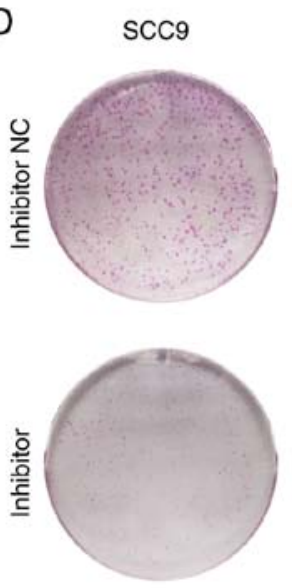

scess

SCC25

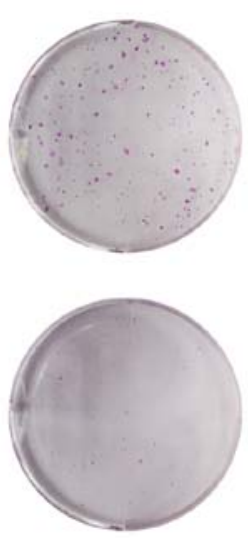

CAL27
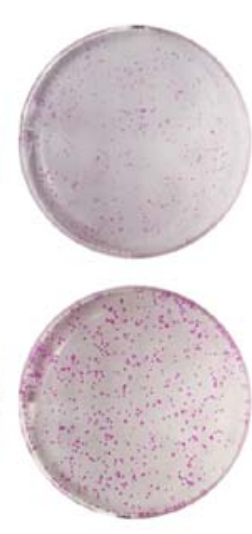

CAL27

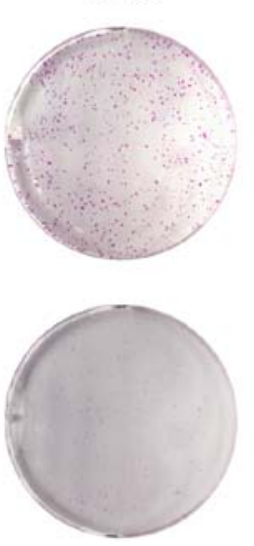

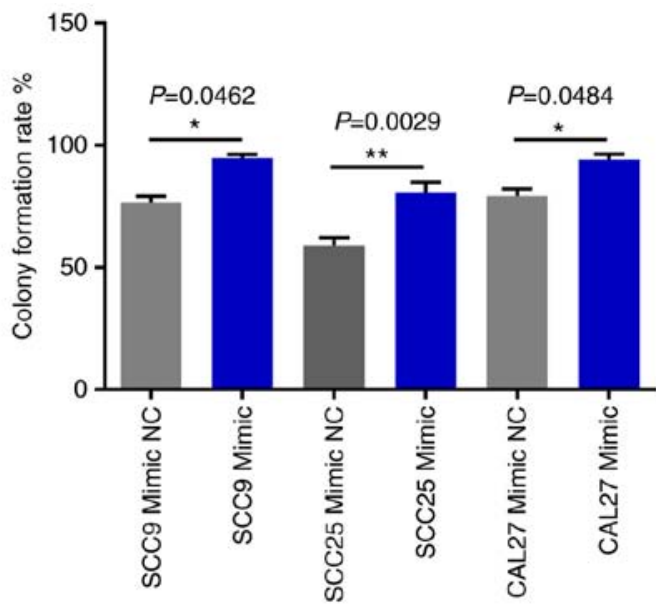

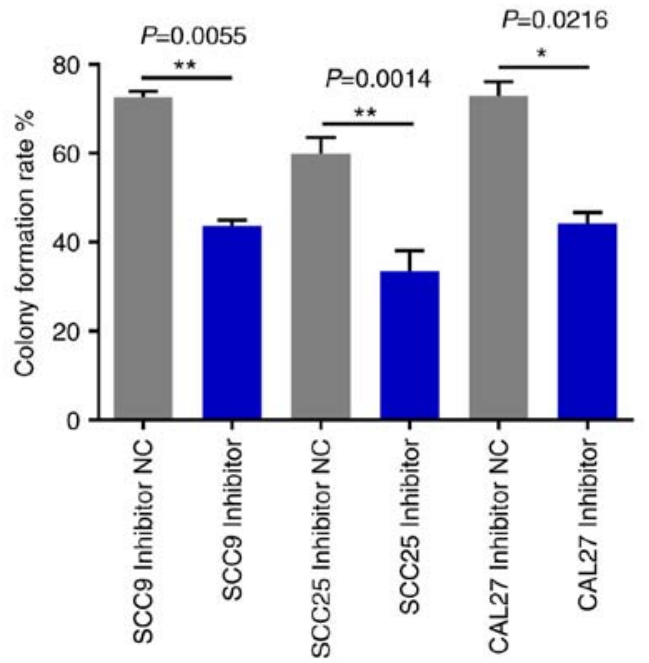

Figure 3. miR-543 promotes the growth of OSCC cell lines in vitro. (A) Cell Counting Kit-8 assay revealed that miR-543 promoted the proliferation of OSCC cell lines following transfection with the miR-543 mimic when compared with the mimic NC or control. (B) miR-543 significantly decreased the proliferation of OSCC cell lines following transfection with the miR-543 inhibitor when compared with the inhibitor NC or control. (C) Colony formation assays demonstrated that miR-543 promoted clone formation in OSCC cell lines following transfection with the miR-543 mimic when compared with mimic NC. (D) miR-543 inhibited colony formation in OSCC cell lines following transfection with the miR-543 inhibitor when compared with the inhibitor NC. " $\mathrm{P}<0.05$, ${ }^{* *} \mathrm{P}<0.01,{ }^{* * *} \mathrm{P}<0.001 ; \mathrm{ns}$, not significant; miR, microRNA; OSCC, oral squamous cell carcinoma; NC, negative control. 
Table III. Partial list of target genes of miR-543 predicted by TargetScan .

\begin{tabular}{|c|c|c|c|}
\hline $\begin{array}{l}\text { Cumulative weighted } \\
\text { context++ score }\end{array}$ & $\begin{array}{l}\text { Representative } \\
\text { miRNA }\end{array}$ & Target gene & Gene name \\
\hline-0.58 & hsa-miR-543 & CYP3A5 & Cytochrome P450, family 3 , subfamily A, polypeptide 5 \\
\hline-0.55 & hsa-miR-543 & $N A N P$ & $\mathrm{~N}$-acetylneuraminic acid phosphatase \\
\hline-0.53 & hsa-miR-543 & $F B X O 34$ & F-box protein 34 \\
\hline-0.45 & hsa-miR-543 & TMEM203 & Transmembrane protein 203 \\
\hline-0.45 & hsa-miR-543 & $T A F 13$ & $\begin{array}{l}\text { TAF13 RNA polymerase II, TATA box binding } \\
\text { protein (TBP)-associated factor, } 18 \mathrm{kDa}\end{array}$ \\
\hline-0.39 & hsa-miR-543 & TNFSF 11 & Tumor necrosis factor (ligand) superfamily, member 11 \\
\hline-0.38 & hsa-miR-543 & $F B X 047$ & F-box protein 47 \\
\hline-0.38 & hsa-miR-543 & $C Y B 5 R 4$ & Cytochrome b5 reductase 4 \\
\hline-0.37 & hsa-miR-543 & $F M N L 2$ & Formin-like 2 \\
\hline-0.37 & hsa-miR-543 & $K I N$ & $\begin{array}{l}\text { KIN, antigenic determinant of recA protein } \\
\text { homolog (mouse) }\end{array}$ \\
\hline-0.37 & hsa-miR-543 & $S C P 2$ & Sterol carrier protein 2 \\
\hline-0.36 & hsa-miR-543 & $P C B P 1$ & poly(rC) binding protein 1 \\
\hline-0.36 & hsa-miR-543 & EIF 1 & Eukaryotic translation initiation factor 1 \\
\hline-0.35 & hsa-miR-543 & SERPINII & $\begin{array}{l}\text { Serpin peptidase inhibitor, clade I (neuroserpin), } \\
\text { member } 1\end{array}$ \\
\hline-0.33 & hsa-miR-543 & C3orf14 & Chromosome 3 open reading frame 14 \\
\hline-0.33 & hsa-miR-543 & ING1 & Inhibitor of growth family, member 1 \\
\hline
\end{tabular}

Table IV. Partial list of target genes of miR-543 predicted by miRDB.

\begin{tabular}{|c|c|c|c|}
\hline Target score & miRNA name & Gene symbol & Gene description \\
\hline 100 & hsa-miR-543 & $F B X O 34$ & F-box protein 34 \\
\hline 99 & hsa-miR-543 & $T B C 1 D 1$ & TBC1 domain family member 1 \\
\hline 99 & hsa-miR-543 & $D M X L 2$ & Dmx like 2 \\
\hline 99 & hsa-miR-543 & ONECUT2 & One cut homeobox 2 \\
\hline 99 & hsa-miR-543 & NWD2 & NACHT and WD repeat domain containing 2 \\
\hline 99 & hsa-miR-543 & $M A P K 1$ & Mitogen-activated protein kinase 1 \\
\hline 99 & hsa-miR-543 & $G P C P D 1$ & Glycerophosphocholine phosphodiesterase 1 \\
\hline 99 & hsa-miR-543 & LIFR & LIF receptor $\alpha$ \\
\hline 99 & hsa-miR-543 & KLHL5 & Kelch like family member 5 \\
\hline 99 & hsa-miR-543 & PER3 & Period circadian regulator 3 \\
\hline 99 & hsa-miR-543 & ANO5 & Anoctamin 5 \\
\hline 98 & hsa-miR-543 & $I L 1 A$ & Interleukin $1 \alpha$ \\
\hline 98 & hsa-miR-543 & FMNL2 & Formin like 2 \\
\hline 97 & hsa-miR-543 & TNFSF 11 & TNF superfamily member 11 \\
\hline 96 & hsa-miR-543 & PRKG1 & Protein kinase cGMP-dependent 1 \\
\hline 96 & hsa-miR-543 & $N R 3 C 1$ & Nuclear receptor subfamily 3 group C member 1 \\
\hline 96 & hsa-miR-543 & $C Y B 5 R 4$ & Cytochrome b5 reductase 4 \\
\hline 93 & hsa-miR-543 & BIRC6 & Baculoviral IAP repeat containing 6 \\
\hline 92 & hsa-miR-543 & ING1 & Inhibitor of growth family member 1 \\
\hline 82 & hsa-miR-543 & $B C L 6 B$ & BCL6B, transcription repressor \\
\hline
\end{tabular}

proliferation of OSCC cell lines (Fig. 3B). In addition, the clone formation rates of the miR-543 mimic groups were increased when compared to the NC groups (Fig. 3C), whereas in the miR-543 inhibitor groups, the opposite results were observed for the clone formation rates of the three cell lines (Fig. 3D). 
A
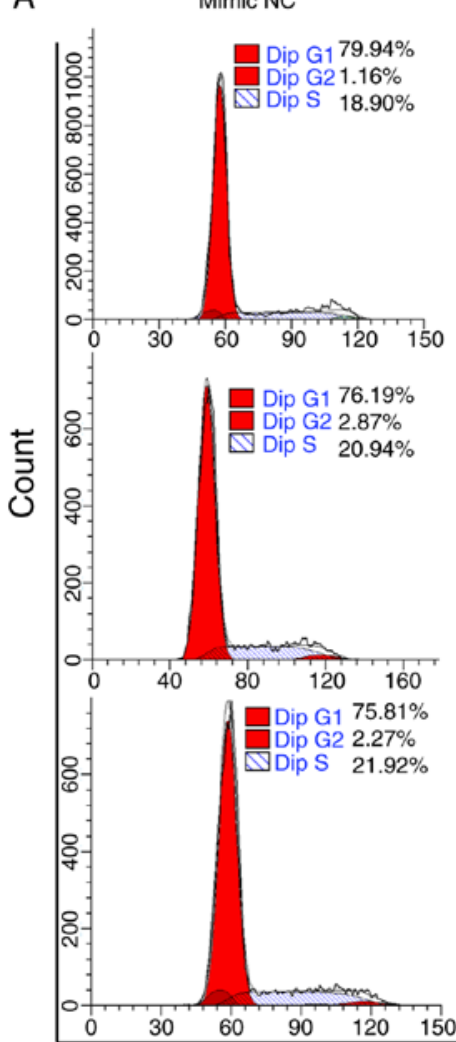
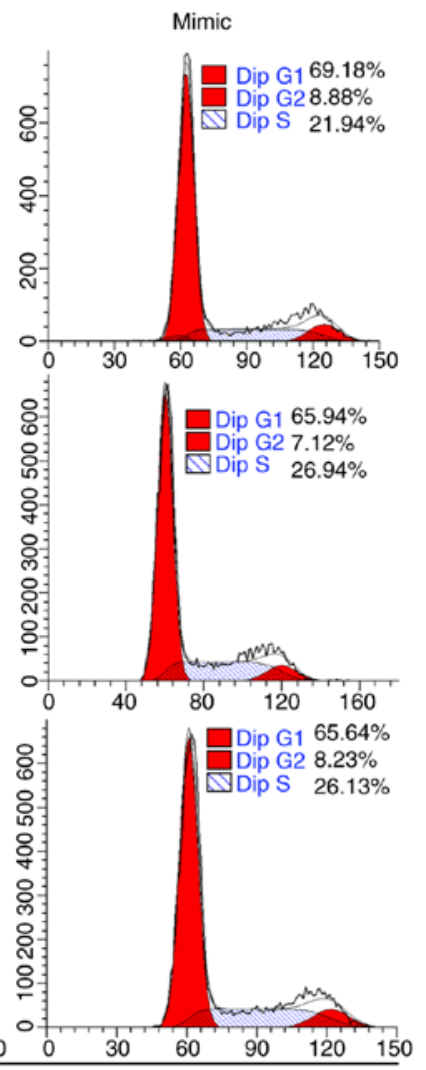

PI
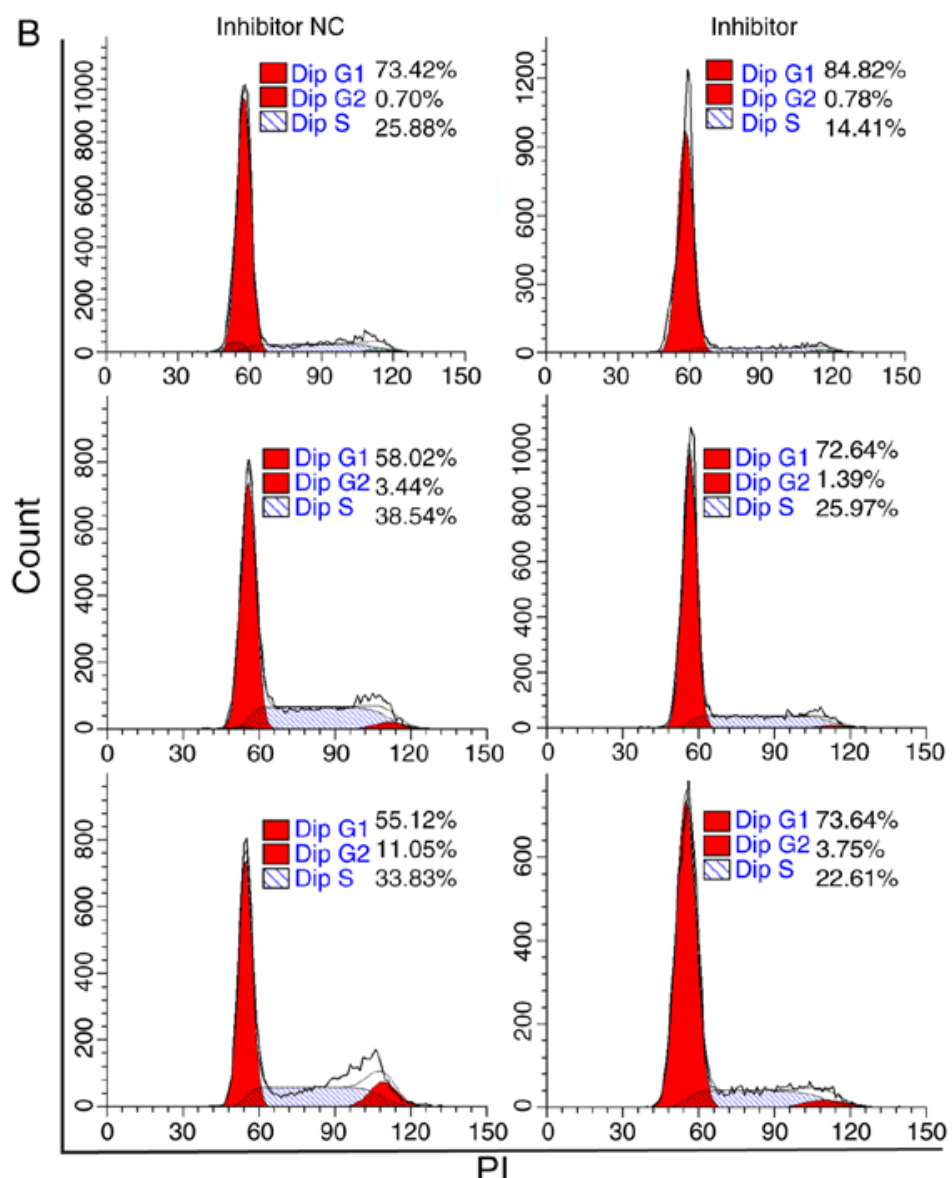

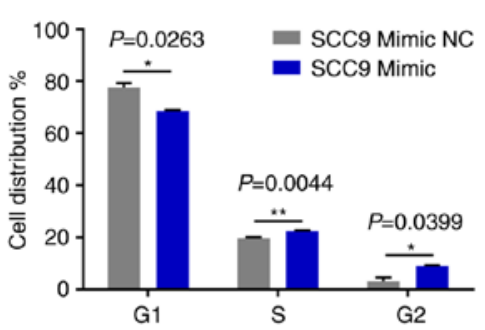

$P=0.0014$
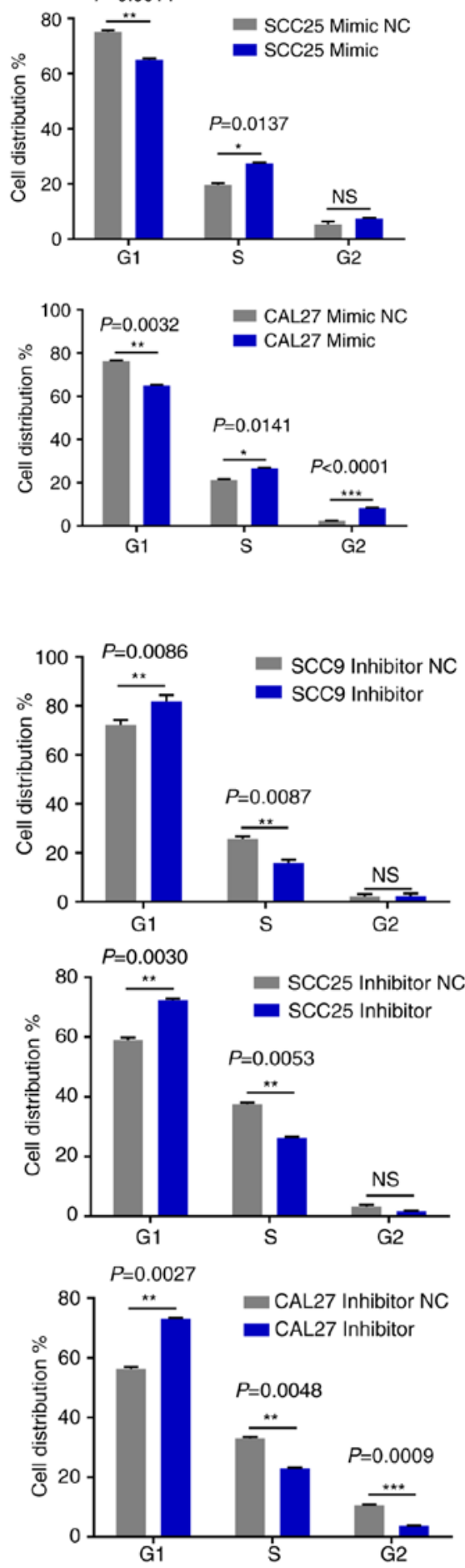

Figure 4. miR-543 promotes the cell cycle of OSCC cell lines. FCM was used to detect the cell cycle. (A) Analysis of the percentage of cells in each phase of the cell cycle was performed in cells transfected with miR-543 mimic; the results revealed that miR-543 mimics promoted cell progression from the G1 phase to the $\mathrm{S}$ and $\mathrm{G} 2$ phases. (B) Transfection with the miR-543 inhibitor inhibited cell cycle progression from the $\mathrm{G} 1$ phase to the $\mathrm{S}$ and $\mathrm{G} 2$ phases. ${ }^{*} \mathrm{P}<0.05$, ${ }^{* *} \mathrm{P}<0.01$, ${ }^{* * *} \mathrm{P}<0.001$; ns, not significant; FCM, flow cytometry; miR, microRNA; OSCC, oral squamous cell carcinoma; NC, negative control. 
A
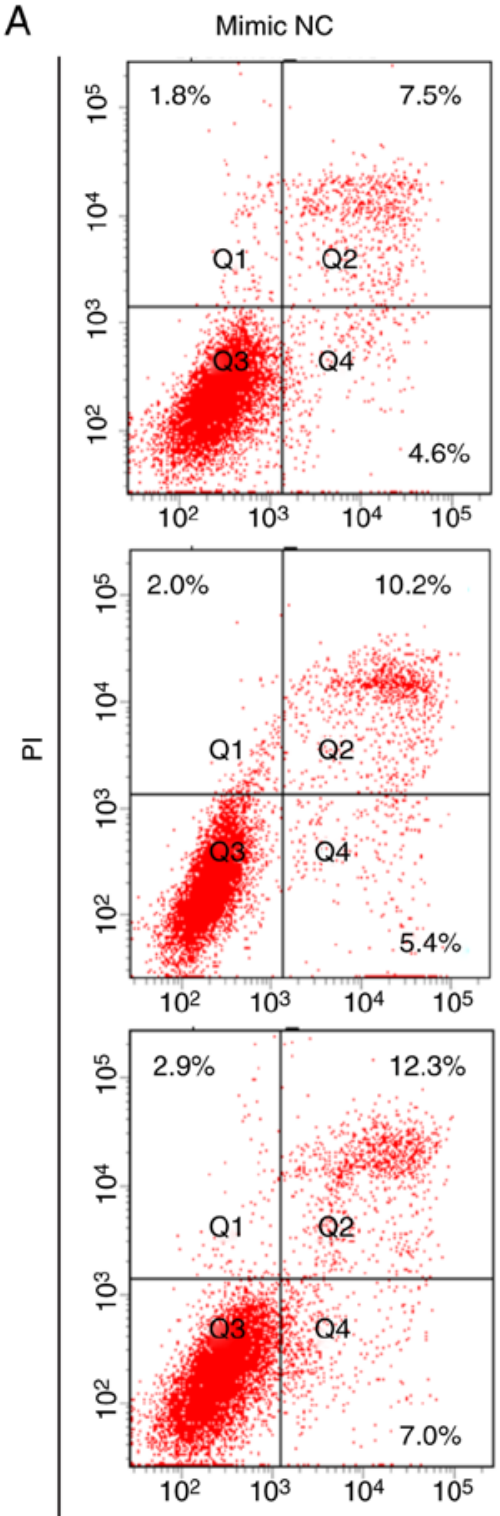
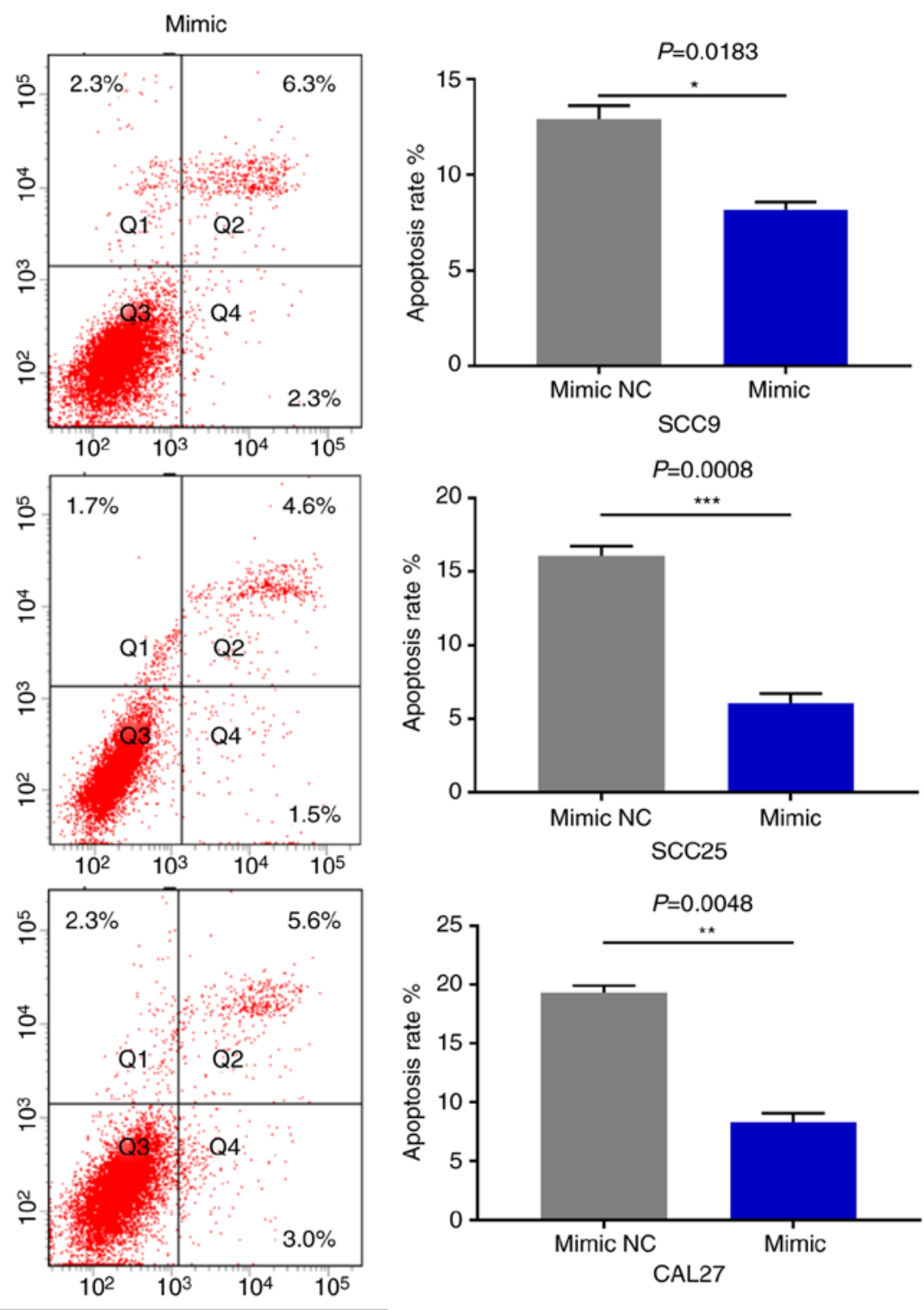

Annexin V FITC

Figure 5. miR-543 inhibits the cell apoptosis of OSCC cell lines. FCM was used to detect the cell apoptosis. (A) FCM revealed that the apoptotic rates of SCC9, SCC25 and CAL27 cells were decreased by 5.07, 9.37 and $10.97 \%$ on average following transfection with the miR-543 mimic, respectively. FCM, flow cytometry; miR, microRNA; OSCC, oral squamous cell carcinoma; NC, negative control.

miR-543 promotes the cell cycle and inhibits cell apoptosis in OSCC cell lines. As miR-543 promoted the proliferation of OSCC cells, the present study then performed cell cycle assays. OSCC cell lines treated with miR-543 mimics had a significantly reduced cell population in the G1 phase and increased cell populations in the $\mathrm{G} 2$ phase when compared with the mimic $\mathrm{NC}$ group, as determined by flow cytometry (Fig. 4A). By contrast, transfection with the miR-543 inhibitors induced G1 arrest in OSCC cell lines (Fig. 4B). Subsequently, cell apoptosis was measured using a flow cytometer. As expected, the apoptotic rate was declined when cells were transfected with miR-543 mimics (Fig. 5A), while the apoptotic rate was increased in the miR-543 inhibitor groups (Fig. 5B). In summary, results indicated that miR-543 may act as an oncogene in OSCC.

miR-543 promotes OSCC cell line invasion and migration. The effects of miR-543 on OSCC cell migration and invasion were then evaluated. The Matrigel Transwell assays revealed that compared with the NC groups, miR-543 mimics significantly increased OSCC cell invasion (Fig. 6A). By contrast, the miR-543 inhibitor groups exhibited markedly reduced invasion in the three cell lines (Fig. 6B). In addition, the Transwell assays demonstrated that overexpression of miR-543 promoted the migration of OSCC cell lines (Fig. 7A); whereas, the miR-543 inhibitor significantly decreased cell migration in the OSCC cell lines (Fig. 7B). The experiments carried out in Figs. 2-7 utilized OSCC cell lines for self-control experiments to observe phenotypic changes of cancer cells by upregulating or downregulating the expression of miR-543 (33).

CYP3A5 is a direct target gene of miR-543. In order to detect miR-543 effector protein molecules, the present study used the bioinformatics website TargetScan to predict the potential target genes of miR-543. Target genes associated with growth 
$\mathrm{B}$
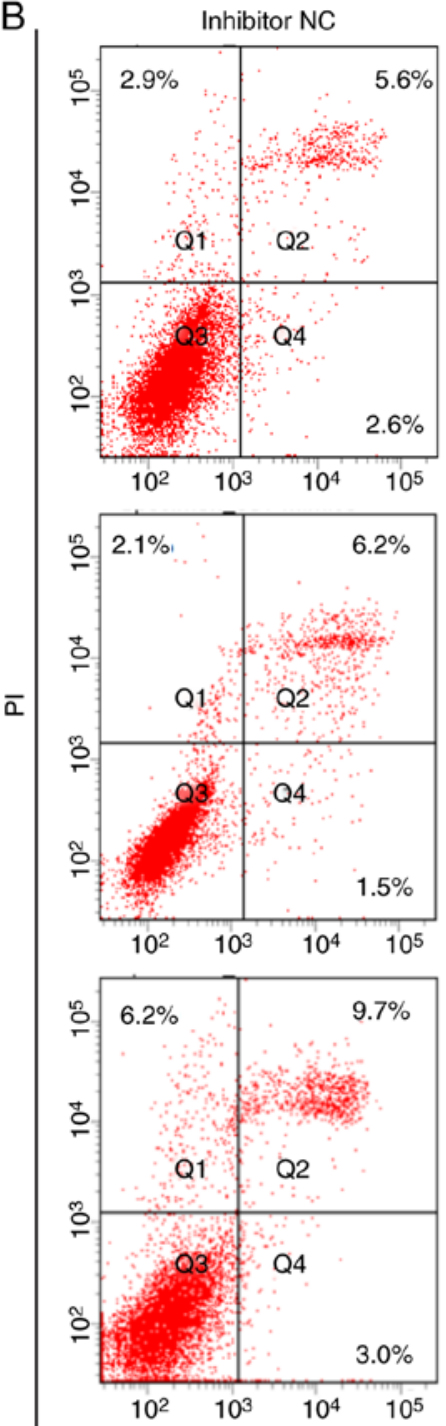
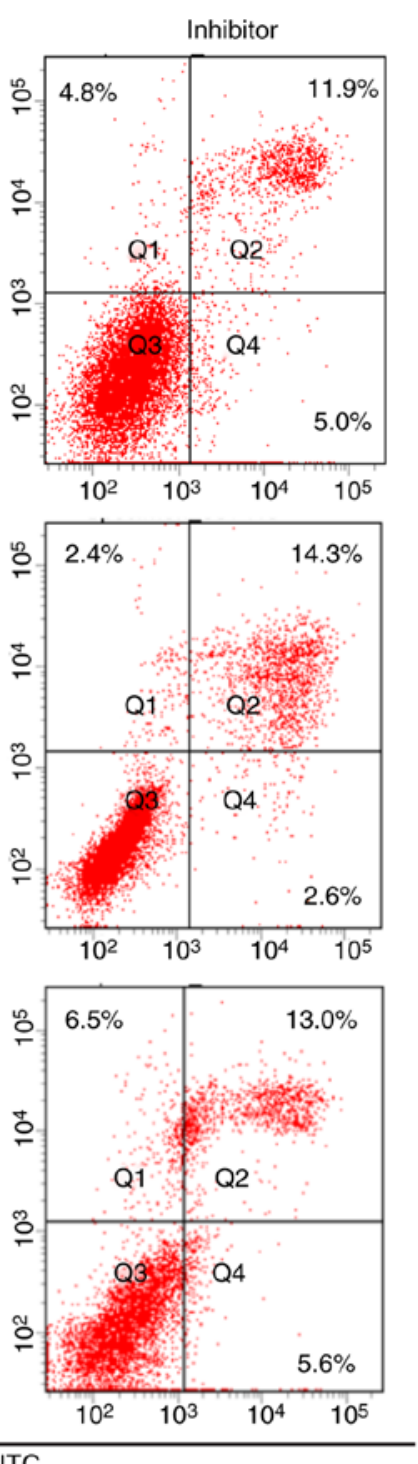
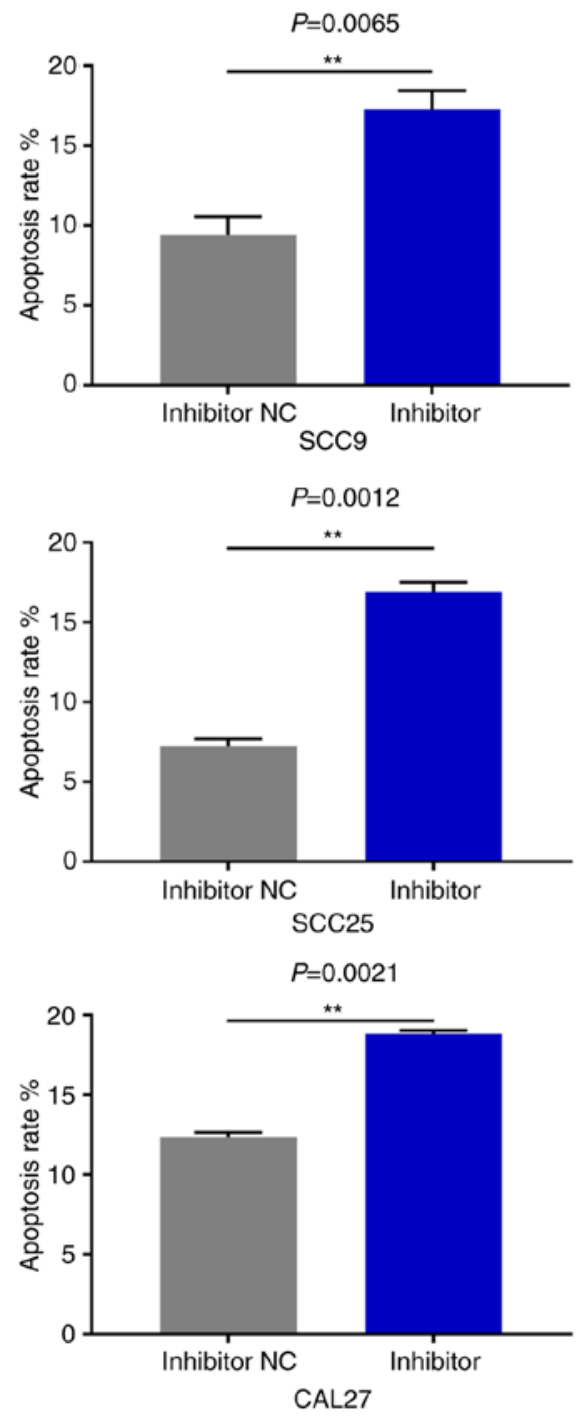

Figure 5. Continued. (B) The apoptotic rates of SCC9, SCC25 and CAL27 cells were increased by $7.83,8.33$ and $7.8 \%$ on average following transfection with the miR-543 inhibitor, respectively. ${ }^{*} \mathrm{P}<0.05,{ }^{* *} \mathrm{P}<0.01,{ }^{* * *} \mathrm{P}<0.001$. FCM, flow cytometry; miR, microRNA; OSCC, oral squamous cell carcinoma; NC, negative control.

or proliferation were screened and then verified in OSCC cell lines. The results revealed that CYP3A5 was significantly negatively correlated with miR-543, and only CYP3A5 was significantly expressed at low levels in the three OSCC cell lines when compared with a number of target genes (Fig. 8A). Therefore, the present study aimed to verify whether CYP3A5 is a downstream target gene of miR-543. First of all, the possible binding sites between CYP3A5 and miR-543 were predicted using TargetScan (Fig. 8B). Then luciferase reporter gene assays were performed using co-transfected miR-543 mimic or mimic NC and the CYP3A5 3' untranslated region (3'UTR) wild-type (WT) or CYP3A5 3'-UTR mutant (MUT) in 293T cells. The overexpression of miR-543 significantly reduced the luciferase activity of WT CYP3A5 3'UTR, while the MUT CYP3A5 3'UTR induced virtually no change (Fig. 8C). Therefore, it was confirmed that CYP3A5 directly binds with miR-543, and that CYP3A5 acts as a downstream target gene of miR-543 in order to exert its influence on OSCC. In addition, the present study measured the changes in the mRNA and protein levels of CYP3A5 by upregulating or downregulating miR-543. The results revealed that the $\mathrm{mRNA}$ and protein expressions of CYP3A5 were decreased following miR-543 overexpression in the three OSCC cell lines (Fig. 8D and F). By contrast, the mRNA and protein expression of CYP3A5 was upregulated following miR-543 knockdown (Fig. 8E and G). In addition, transfection with CYP3A5 siRNA significantly reduced the expression levels in SCC9 cells (Fig. 9A). It was also demonstrated that reducing the expression of CYP3A5 promoted the proliferation of SCC9 cells (Fig. 9B) and promoted the invasion of SCC9 cells (Fig. 9C). In summary, CYP3A5 may be a direct target gene of miR-543 in OSCC cell lines.

CYP3A5 is negatively associated with miR-543 expression in OSCC. The expression pattern of miR-543 and CYP3A5 was next analyzed in OSCC. The results demonstrated that CYP3A5 was weakly expressed in the 20 pairs of OSCC tissues when compared with the adjacent non-tumor tissues, as determined by RT-qPCR (Fig. 10A and B); it was also inversely correlated with the expression of miR-543 in OSCC samples (Fig. 1A and B). In addition, correlation analysis 
A
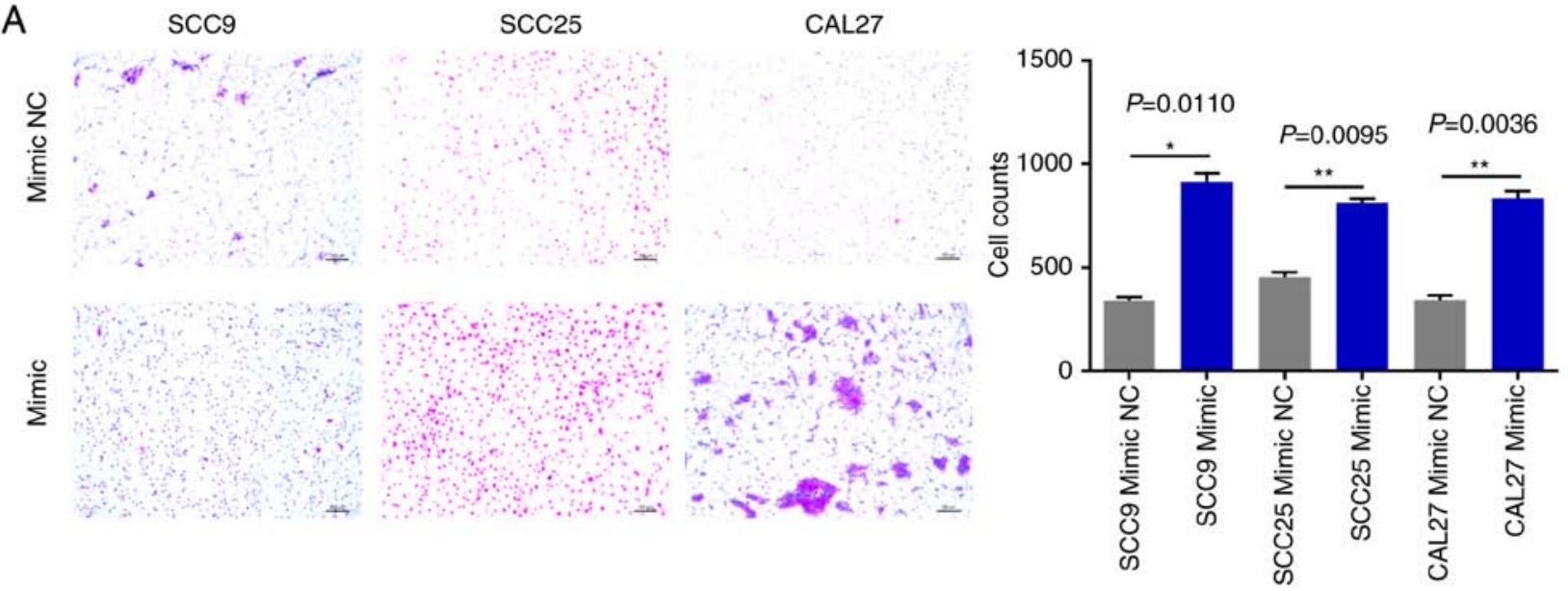

CAL27

B
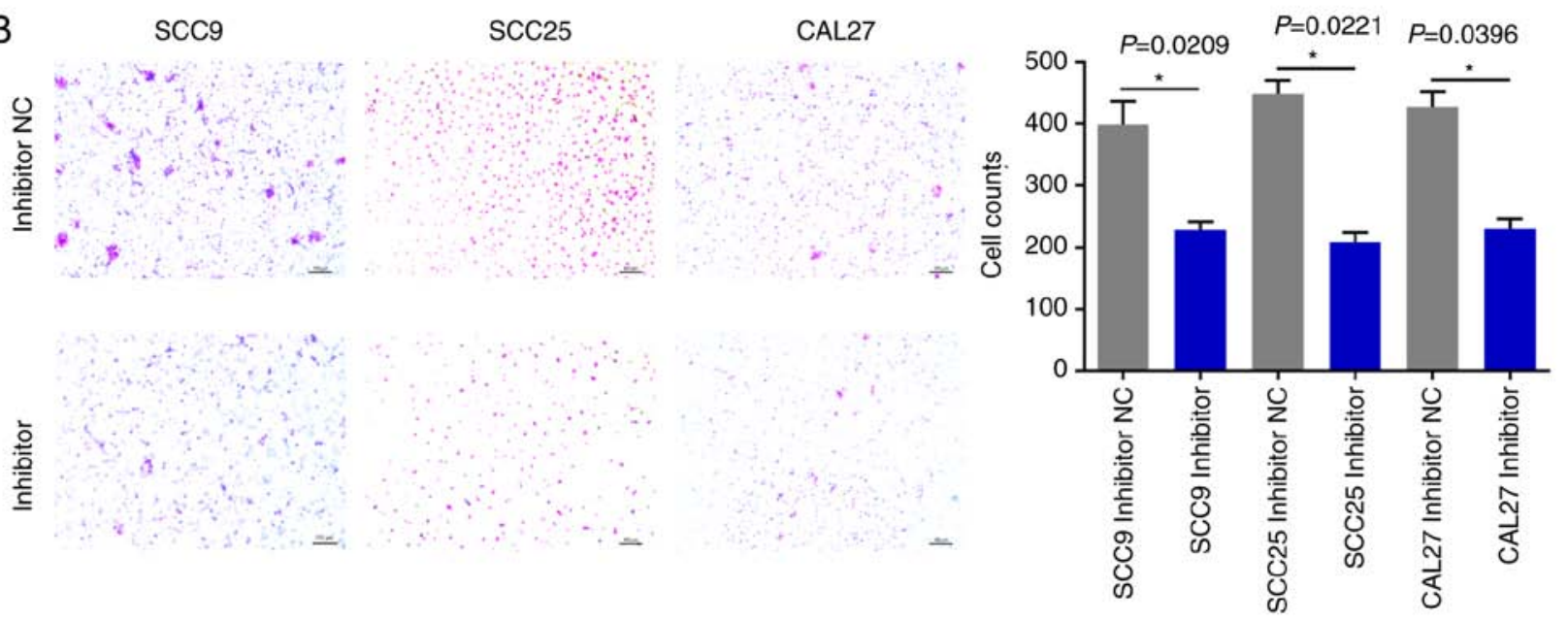

Figure 6. miR-543 promotes OSCC cell invasion. (A) Transwell invasion assay analysis revealed that SCC9, SCC25 and CAL27 cells transfected with the miR-543 mimic exhibited increased cell invasion when compared with the mimic NC. (B) SCC9, SCC25 and CAL27 cells transfected with the miR-543 inhibitor had decreased cell invasion when compared with the inhibitor NC. ${ }^{*} \mathrm{P}<0.05,{ }^{* *} \mathrm{P}<0.01$. miR, microRNA; OSCC, oral squamous cell carcinoma; $\mathrm{NC}$, negative control.

$(y=-2.923 x+2.668)$ of the expression levels of CYP3A5 and miR-543 was conducted in 20 pairs of OSCC tissues. Then we use the Enter method to verify the equation to obtain $\mathrm{F}=11.71$, $\mathrm{P}=0.0030$, statistically significant. The results revealed that there was a significant negative correlation between CYP3A5 and miR-543, and the results were consistent with those of our predictions (Fig. 10C). Therefore, it was further demonstrated that miR-543 targets CYP3A5 in OSCC to serve specific roles. Similarly, CYP3A5 was significantly downregulated in OSCC cell lines (Fig. 10D) and was negatively correlated with the expression levels of miR-543 (Fig. 1C). In the present study, miR-543 was expressed at a higher level in the SCC25 than the SCC9 and CAL27 cells (Fig. 1C), and the expression of CYP3A5 was also expressed at a higher level in SCC25 than the SCC9 and CAL27 cells (Fig. 10D). The reason may be that one miRNA may target multiple genes, and the expression level of each target gene may vary. Therefore, miR-543 suppressed the expression of CYP3A5 in this study, but it is also possible that the expression of CYC3A5 is relatively higher in SCC25 than in SCC9 and CAL27 cells. The experiments were repeated at least three times, and we confirmed that the levels of expression of CYC3A5 were relatively higher in SCC25 cells than levels in the SCC9 and CAL27 cells.
Next, IHC assays were performed to evaluate CYP3A5 expression in 20 OSCC specimens (Fig. 11). The expression of CYP3A5 was analyzed in cancerous tissues, comparing OSCC tissues with adjacent non-tumor tissues. CYP3A5 consistently exhibited positive expression in OSCC adjacent non-tumor tissues; however, the rate of CYP3A5 positive expression was significantly lower in cancerous tissues. The findings revealed that the expression of CYP3A5 in each tumor stage was lower than that in the paracancerous tissue, but there was no significant difference between each stage. This result is consistent with the results of the biological website analysis of the expression of CYP3A5 in each stage of HNSC (27).

UALCAN data were then used to analyze the gene CYP3A5 expression in HNSC. Data from TCGA revealed that when compared with normal tissues, CYP3A5 exhibited a lower expression level in cancerous tissues, as well as low expression levels in all four stages of the tumor (Fig. 12A). The expression of CYP3A5 in various clinical stages of HNSC was then investigated. Similarly, low expression levels of CYP3A5 were also observed in each stage (Fig. 12B). These results are consistent with the above experimental results. In addition, the expression analysis of CYP3A5 in HNSC tumor stages also revealed low expression levels of CYP3A5 in each tumor stage (Fig. 12C). These results correspond with the previous 
A
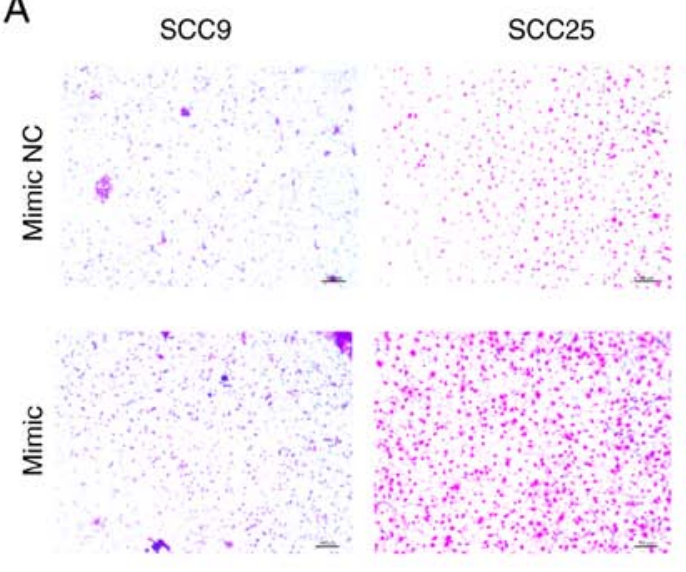

B

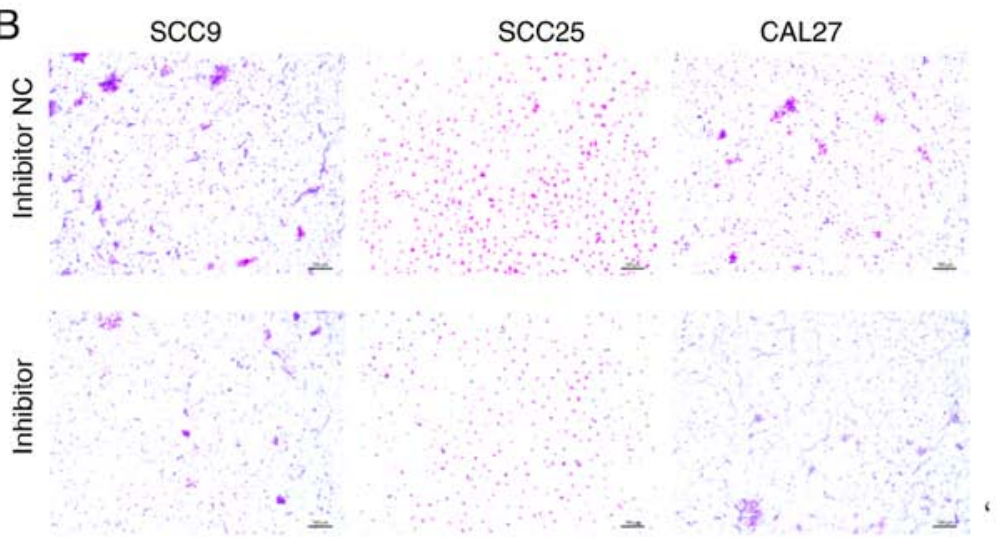

CAL27
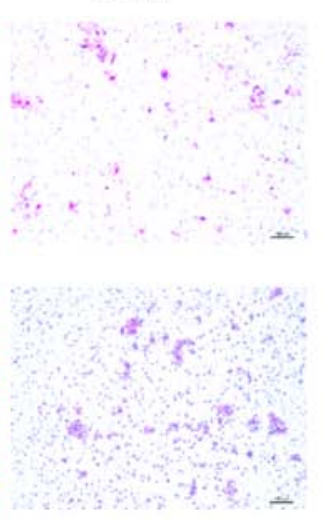
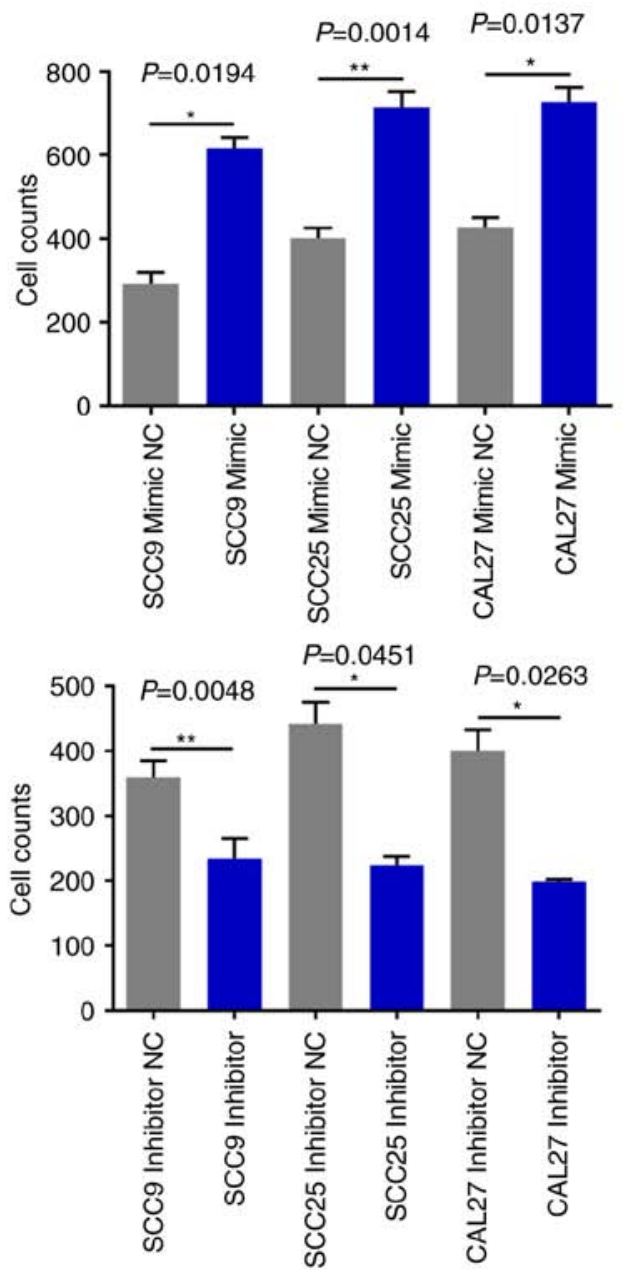

Figure 7. miR-543 promotes OSCC cell migration. (A) Transwell migration assay analysis demonstrated that SCC9, SCC25 and CAL27 cells transfected with the miR-543 mimic exhibited increased cell migration when compared with the mimic NC. (B) SCC9, SCC25 and CAL27 cells transfected with the miR-543 inhibitor had decreased cell migration when compared with inhibitor $\mathrm{NC} .{ }^{*} \mathrm{P}<0.05,{ }^{* *} \mathrm{P}<0.01$. miR, microRNA; OSCC, oral squamous cell carcinoma; $\mathrm{NC}$, negative control.

results of the present study. Taken together, this analysis revealed that CYP3A5 expression may be negatively correlated with miR-543 expression.

High expression of miR-543 predicts the poor prognosis of HNSC patients. Survival analysis was also performed to evaluate whether miR-543 expression levels could predict HNSC prognosis. OncoLnc was employed to analyze the associations between miRNA or mRNA expression with survival, using all of the TCGA data obtained. Kaplan-Meier Plot analysis demonstrated that patients with higher levels of miR-543 had significantly poorer survival than patients with lower miR-543 expression levels (Fig. 12D; log-rank $\mathrm{P}=0.0124$ ). These results indicated that miR-543 may be closely associated with the prognosis of patients.

\section{Discussion}

Oral squamous cell carcinoma (OSCC) is one of the most common types of malignancies worldwide. Although the treatment of patients with oral cancer has improved in recent years, the overall 5-year survival rate has shown no significant improvement, remaining at $\sim 50 \%$ (34). Thus, the development of novel targets for clinical therapy is urgently required and clinically significant. Therefore, understanding the pathogenesis of OSCC and identifying novel gene therapy options has been a key area of interest in recent years. miRNA expression has been associated with the occurrence and progression of various tumors and miRNAs have been revealed to act as tumor-suppressor genes or oncogenes (35-38). It has also been demonstrated that aberrantly expressed miRNAs can regulate OSCC progression and that miRNAs may become targets for future therapy (39-42).

Previous studies have demonstrated that miR-543 may act as a tumor-suppressor gene or oncogene $(43,44)$. Earlier research found that miR-543 exhibits low expression in glioma, and induced tumor cell apoptosis, inhibited growth, the cell cycle, migration and the invasion of cancer cells (45). In previous research, it was demonstrated that miR-543 suppressed breast cancer cell proliferation, cell cycle and induced apoptosis by the extracellular signal-regulated kinase-2 (ERK2)/mitogen-activated protein kinase (MAPK) signaling pathway, and the phosphorylation of downstream factors including RSK2 and MSK1 was impeded (15). However, the present study did not further verify whether miR-543 affects OSCC through the ERK2/MAPK signaling pathway, 
A

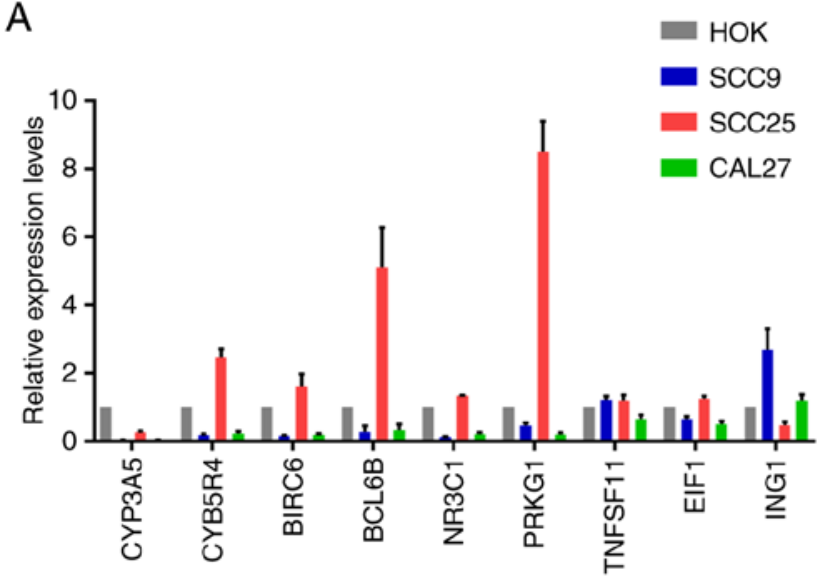

B hsa-miR-543:

CYP3A5 3'UTR WT:

CYP3A5 3'UTR MUT:
3' uucuucacguggcgc UUACAAa $5^{\prime}$

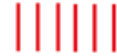

5 ' gacuauggcuguccaAAUGUUc $3^{\prime}$

5 ' gacuauggcuguccaGUCAGCc 3 '
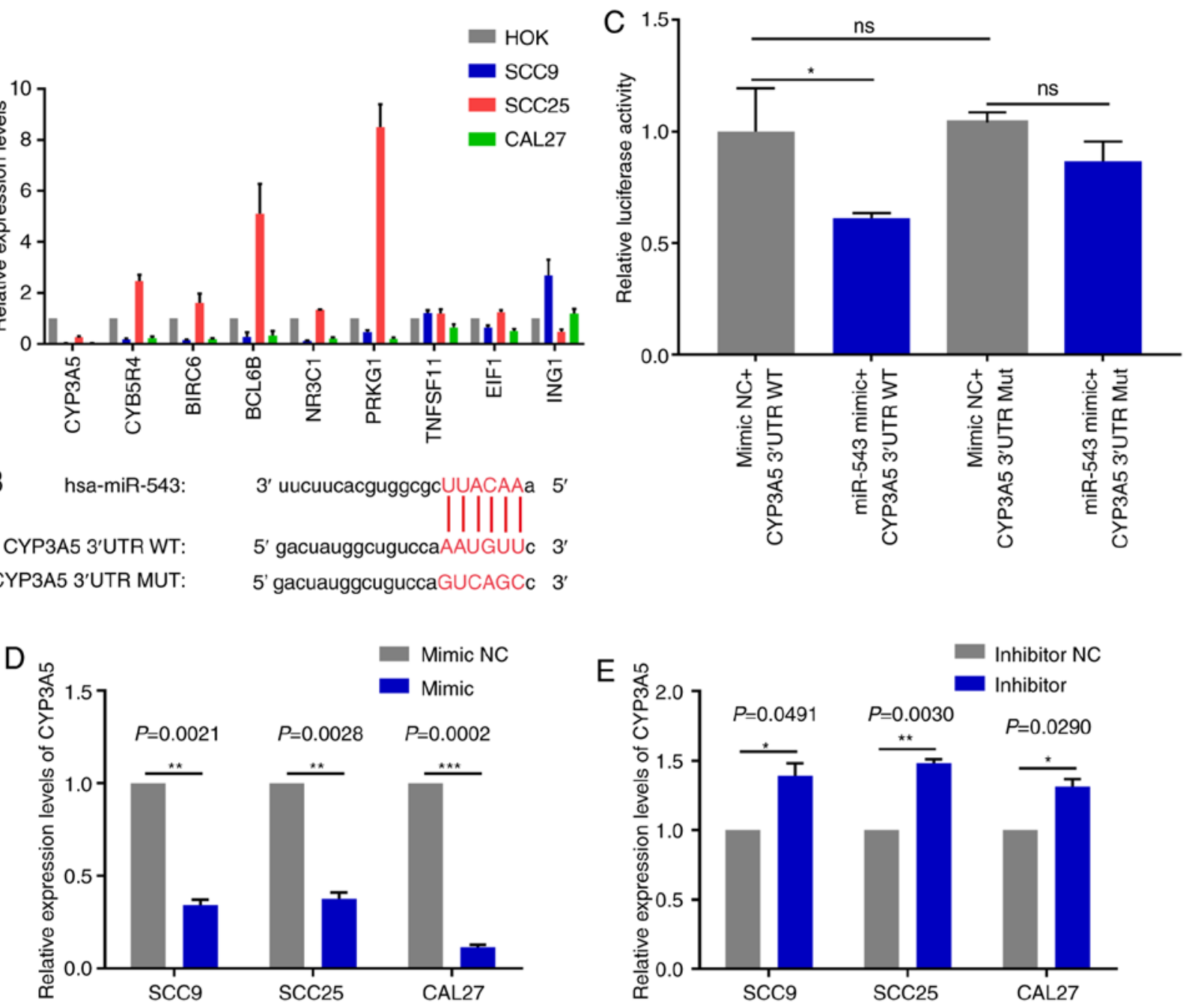

F

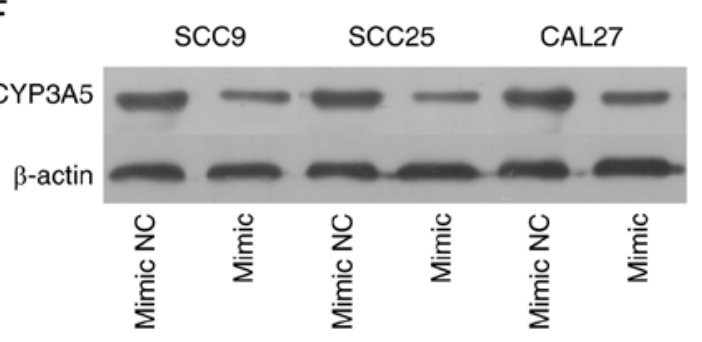

G

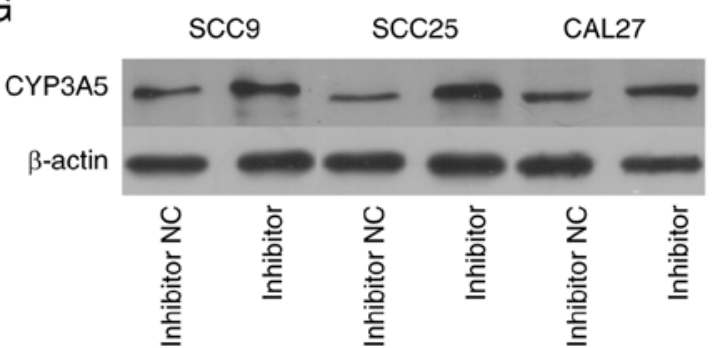

Figure 8. CYP3A5 is a direct target gene of miR-543. (A) The screened target genes were initially validated in OSCC cell lines, and it was determined that the expression level of CYP3A5 had an inverse correlation with miR-543 in the OSCC cell lines. (B) The sequence of the miR-543 binding site within the 3'UTR of human CYP3A5. (C) CYP3A5 had a direct binding role with miR-543. Analysis of the relative luciferase activities of CYP3A5-WT and CYP3A5-MUT in 293T cells. The results revealed that overexpression of miR-543 significantly reduced the luciferase activity of WT CYP3A5 3'UTR, while the MUT CYP3A5 3'UTR had virtually no change. CYP3A5 (D) mRNA and (F) protein expression were decreased in SCC9, SCC25 and CAL27 cells following treatment with miR-543 mimic when compared with the mimic NC. CYP3A5 (E) mRNA and (G) protein expression were decreased in SCC9, SCC25 and CAL27 cells following treatment with the miR-543 inhibitor when compared with the inhibitor NC. ${ }^{*} \mathrm{P}<0.05,{ }^{* *} \mathrm{P}<0.01,{ }^{* * *} \mathrm{P}<0.001$; ns, not significant; miR, microRNA; OSCC, oral squamous cell carcinoma; NC, negative control; CYP3A5, cytochrome P450 family 3 subfamily A member 5; UTR, untranslated region; MUT, mutant; WT, wild-type.

which will be a direction for subsequent research. In addition, miR-543 exhibited a similar decrease in colorectal cancer and inhibited the growth, invasion and metastasis of colon cancer by targeting kirsten rat sarcoma viral oncogene homolog, metastasis-associated 1 and high mobility group AT-hook 2 genes (46). However, additional studies have revealed that miR-543 is highly expressed in colorectal cancer (16). In addition, miR-543 was upregulated in lung cancer, and promoted the cell proliferation and invasion of non-small cell lung cancer by targeting phosphatase and tensin homolog protein (12). In gastric cancer and osteosarcoma, miR-543 was observed to be overexpressed and to serve as an oncogene to promote cancer cell proliferation and glycolysis $(13,47)$. Furthermore, miR-543 was also found to be highly expressed in prostate cancer and was confirmed to directly target receptor-interacting serine/threonine-protein kinase 1 to promote cell proliferation 


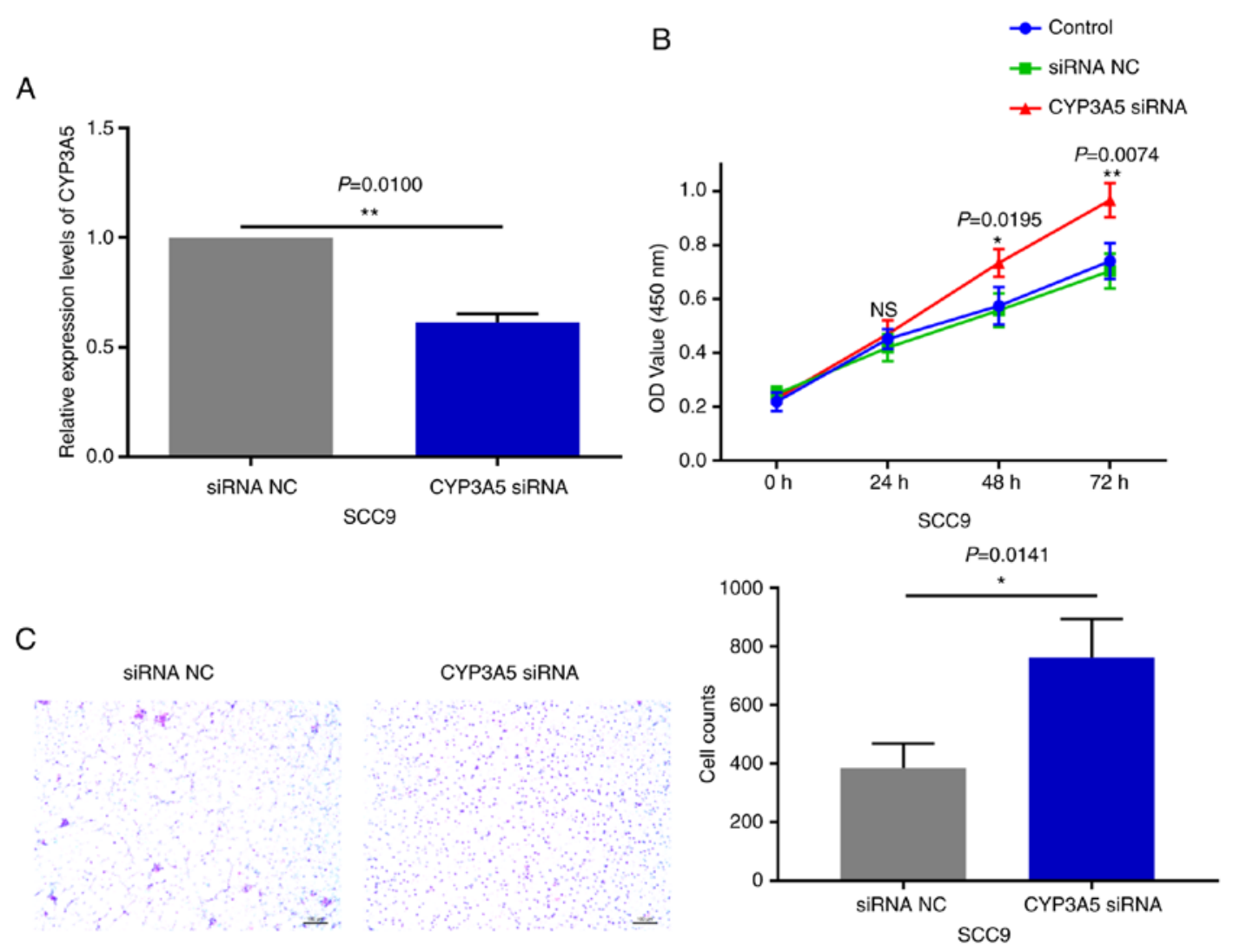

Figure 9. Effects of CYP3A5 on the phenotypes of SCC9 cells. (A) CYP3A5 expression was significantly downregulated in SCC9 cells following transfection with CYP3A5 siRNA when compared with NC. Knockdown of CYP3A5 in SCC9 cells promoted (B) cell proliferation and (C) invasion. ${ }^{*} \mathrm{P}<0.05,{ }^{* * *} \mathrm{P}<0.01$; ns, not significant; NC, negative control; CYP3A5, cytochrome P450 family 3 subfamily A member 5; siRNA, small interfering.
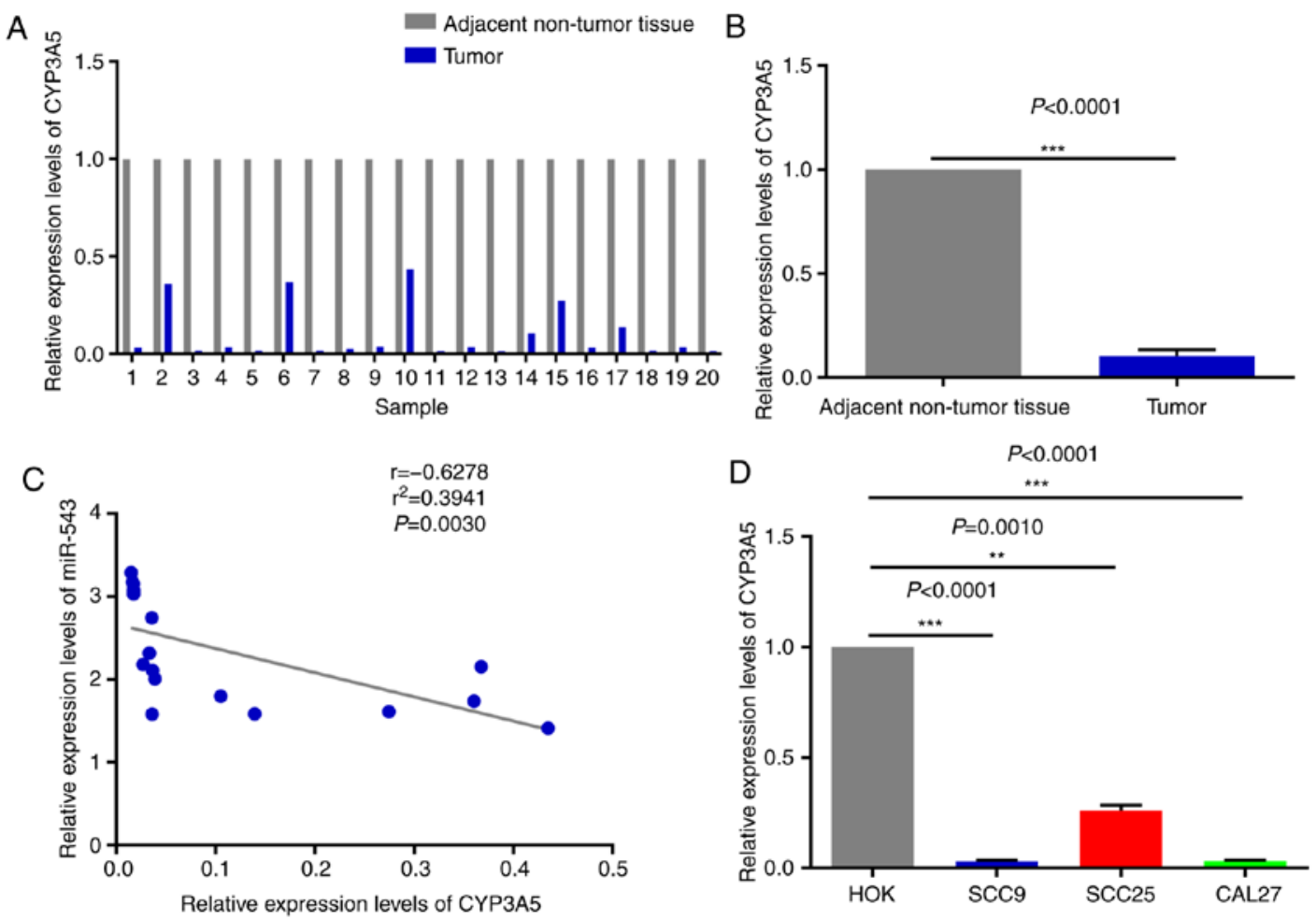

Figure 10. CYP3A5 is negatively associated with miR-543 expression in OSCC. (A and B) RT-qPCR analysis of the level of CYP3A5 revealed a decrease in cancerous tissues when compared with that in the adjacent non-tumor tissues according to the results detected in 20 paired clinical samples. (C) Analysis of the correlation of expression levels of CYP3A5 and miR-543 in 20 pairs of OSCC. The results revealed that there was a significant negative correlation between CYP3A5 and miR-543. (D) RT-qPCR analysis determined that CYP3A5 was significantly decreased in the 3 OSCC cell lines when compared with HOK cells. ${ }^{* *} \mathrm{P}<0.01,{ }^{* * *} \mathrm{P}<0.001$. miR, microRNA; OSCC, oral squamous cell carcinoma; CYP3A5, cytochrome P450 family 3 subfamily A member 5; RT-qPCR, reverse transcription-quantitative polymerase chain reaction. 

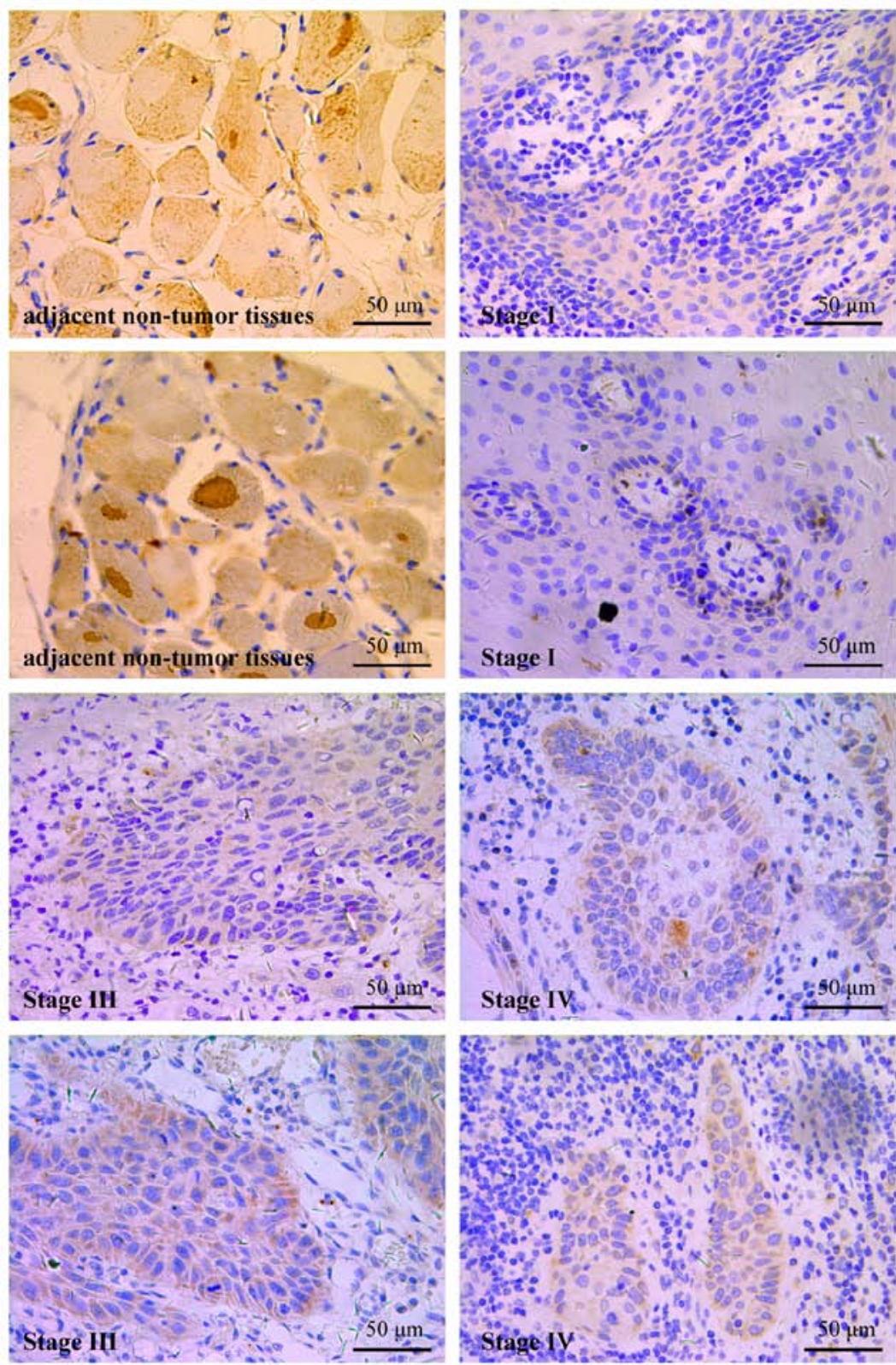
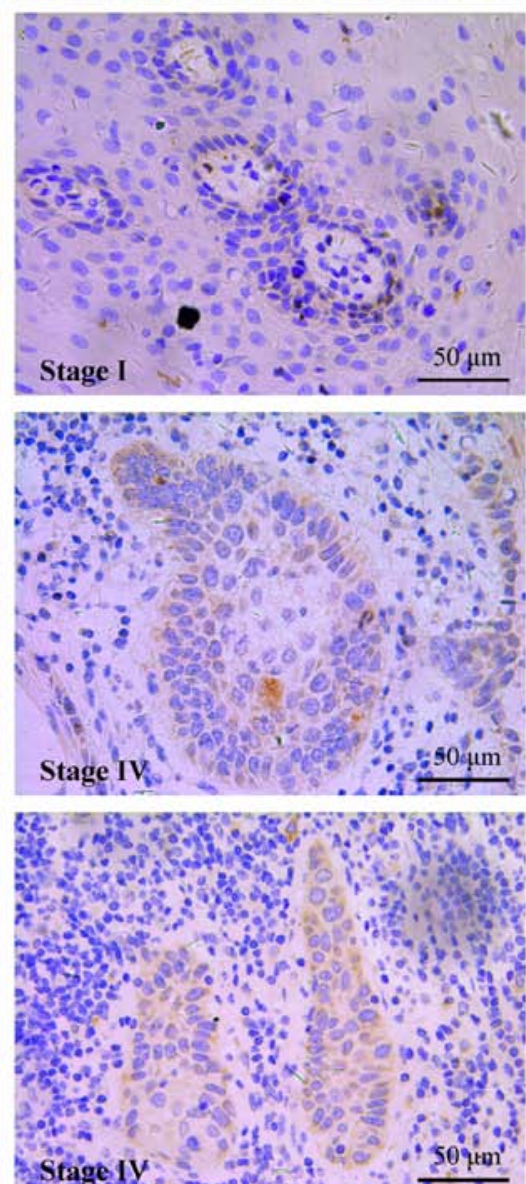
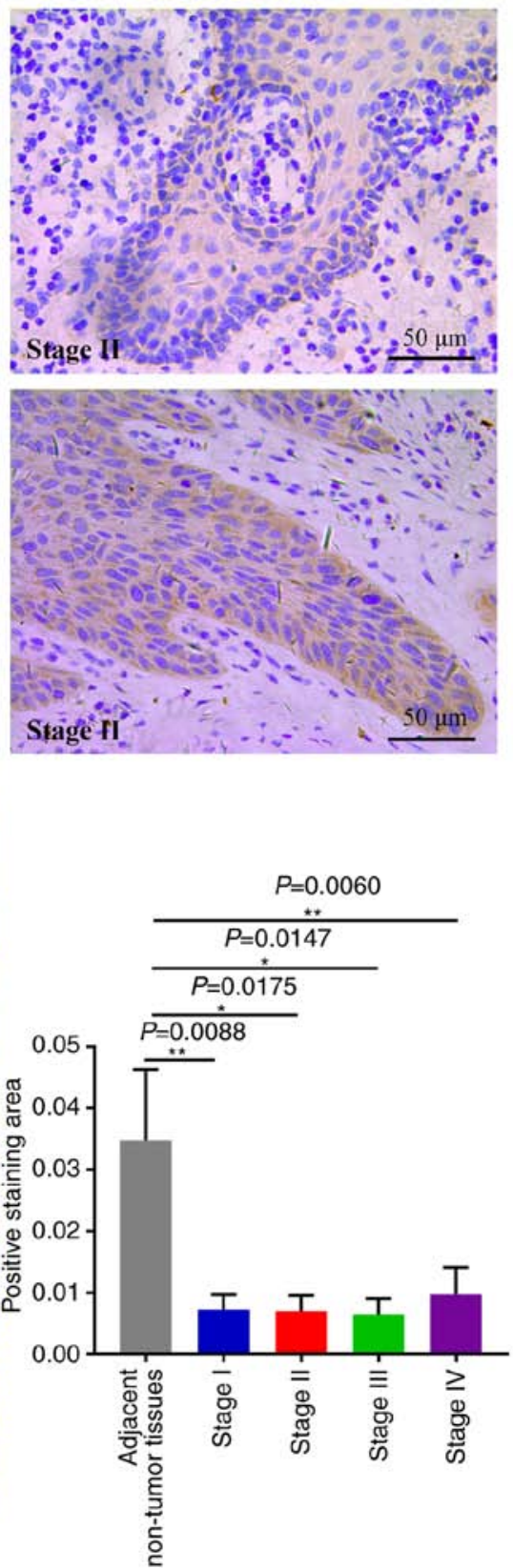

Figure 11. Immunohistochemical analysis of the expression levels of CYP3A5; the expression was low in OSCC tissues when compared with that in the adjacent non-tumor tissues. ${ }^{*} \mathrm{P}<0.05,{ }^{* * *} \mathrm{P}<0.01$. CYP3A5, cytochrome $\mathrm{P} 450$ family 3 subfamily A member 5 .

and induce epithelial-mesenchymal transition, which promoted cell invasion and migration in vitro and in vivo (48).

However, the expression and the biological function of miR-543 in OSCC are still unclear. It was proposed that miR-543 may serve an important role in OSCC. Firstly, in the present study, miR-543 expression was revealed to be significantly upregulated in human OSCC tissues when compared with that noted in paired adjacent non-cancerous normal tissues. Similarly, miR-543 was also significantly upregulated in three OSCC cell lines. miR-543 overexpression and knockdown models were established in SCC9, SCC25 and CAL27 cell lines. The results demonstrated that overexpression of miR-543 in the three OSCC cell lines promoted cell proliferation, invasion, migration and cell cycle progression from the G1 phase to the $\mathrm{S}$ and $\mathrm{G} 2$ phases, whereas cell apoptosis was suppressed. By contrast, inhibition of miR-543 suppressed the proliferation, invasion, migration and cell cycle progression of OSCC, while the levels of cell apoptosis were elevated. Taken together, the results suggested that miR-543 may act as a potential oncogene that contributes to the progression, invasion and metastasis of OSCC. But the absence of a non-cancerous cell line as a negative control and the absence of an untreated cell group are the limitations of this study.

In the present study, CYP3A5 was identified as a direct target of miR-543. The supporting results were as follows: i) A complementary sequence of miR-543 was identified by site prediction in the 3'UTR of CYP3A5 mRNA; ii) the expression levels of miR-543 and CYP3A5 were negatively correlated in OSCC; and iii) the overexpression of miR-543 resulted in a significant decrease in CYP3A5 at the mRNA and protein levels, whereas the inhibition of miR-543 resulted in the opposite outcome. The overexpression of miR-543 inhibited 
A
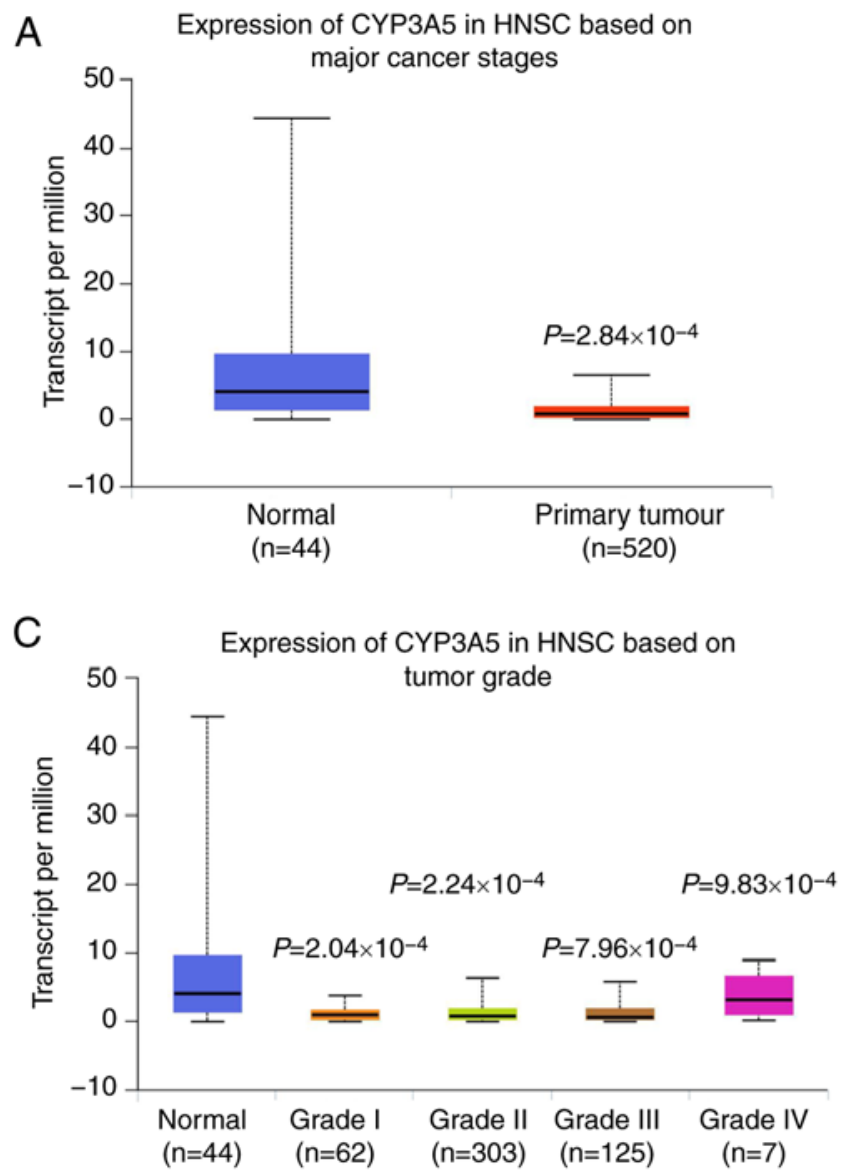

B Expression of CYP3A5 in HNSC based on

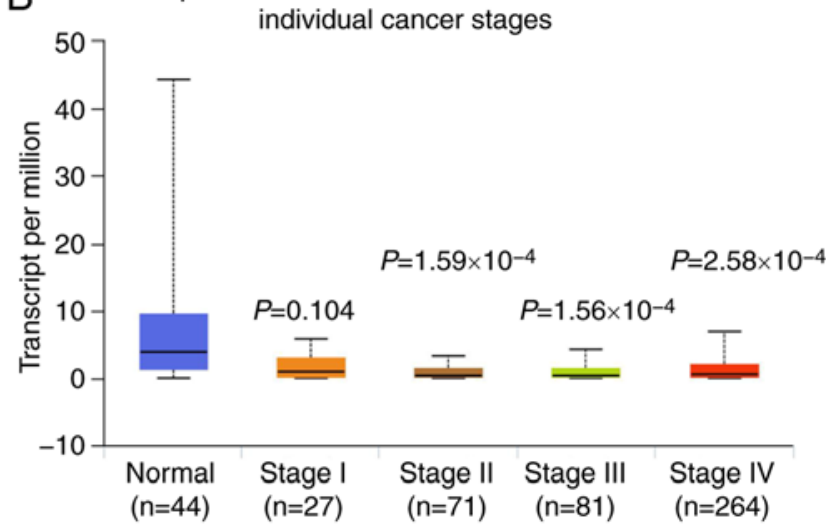

D ha-miR-543

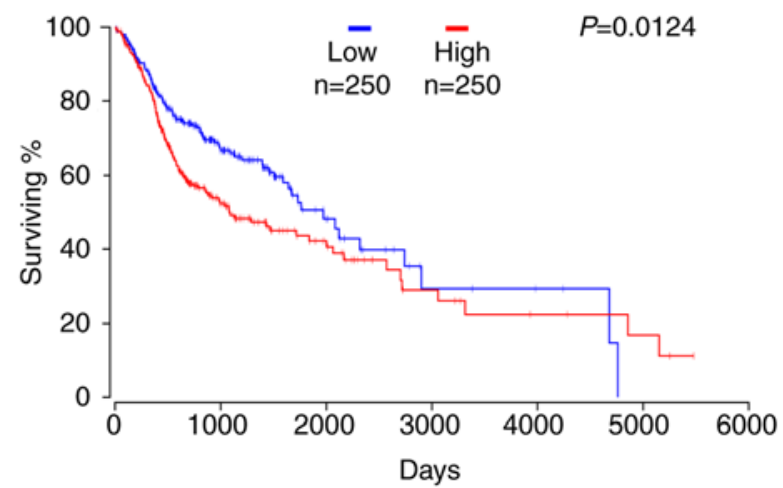

Figure 12. high expression levels of miR-543 predicts the poor prognosis of HNSC patients. (A) Data from TCGA demonstrated that when compared with normal tissues, CYP3A5 exhibited lower expression levels in cancerous tissues. (B) Low expression levels of CYP3A5 in the individual cancer stages. (C) Low expression levels of CYP3A5 in the tumor grades. (D) High expression levels of miR-543 predicted poor prognosis in HNSC patients. Data from TCGA revealed that miR-543 at a high level of expression equated to a poorer survival prognosis in HSNC patients. TCGA, The Cancer Genome Atlas; miR, microRNA; CYP3A5, cytochrome P450 family 3 subfamily A member 5; HNSC, head and neck squamous cell carcinoma.

CYP3A5 3'UTR luciferase reporter activity and this effect was attenuated via mutations in the miR-543 seed binding site. These results indicated that miR-543 may function as a tumor oncogene in OSCC mediated by the inhibition of CYP3A5 expression.

CYP3A5 is one of the major members of the cytochrome P450 CYP3A subfamily, and has been the focus of many previous studies investigating the associations with drug metabolism, CYP3A5 polymorphism and cancer risk (49-53). In recent years, many studies have revealed that CYP3A5 is abnormally expressed in a variety of tumors, while its abnormal expression is closely associated with tumor invasion and metastasis $(54,55)$. In previous research, CYP3A5 was demonstrated to be highly expressed in patients with osteosarcoma and to be associated with metastasis and prognosis; thus, CYP3A5 may serve as a biomarker of osteosarcoma (56). In addition, the expression level of CYP3A5 was significantly decreased in HCC and inhibited the invasion and metastasis of HCC through the transducer of regulated cAMP response binding element-binding protein 2/protein kinase B signaling pathway (22). Consistent with these, the results of the present study indicated that the expression of CYP3A5 is reduced in human OSCC. CYP3A5 is a direct target gene of miR-543, and its expression is negatively correlated with miR-543 levels in OSCC. In addition, upregulation of miR-543 may promote cell proliferation, invasion and migration by inhibiting the expression of CYP3A5 in the OSCC cell lines.

In conclusion, the present study highlights the important role of miR-543 in promoting the cell proliferation, invasion and migration of OSCC cells by repressing of the expression of CYP3A5. The results indicate that miR-543 may serve as a potential biomarker and treatment target for OSCC in the future.

\section{Acknowledgements}

The authors would like to thank Stomatology Hospital of Guangzhou Medical University for kindly providing the OSCC samples for the present study. The authors also thank Dr Zhichao Zheng (Key Laboratory of Oral Medicine, Guangzhou Institute of Oral Disease, Stomatology Hospital of Guangzhou Medical University, Guangzhou, Guangdong, China) for his great help in writing this paper.

\section{Funding}

The present study was supported by Science and Technology Project of Guangdong (grant no. 2013B021800186), the Project of Department of Education of Guangdong Province (grant no. 2017KQNCX162) and the Project of Guangzhou Municipal Health Commission (grant no. 20181A011103). 


\section{Availability of data and materials}

The datasets used and/or analyzed during the current study are available from the corresponding author on reasonable request.

\section{Authors' contributions}

WC, JZ, YW, XC and XZ performed the experiments and analyzed the data. LW, LG and YY guided the experiments and designed the study. WC and JZ wrote the manuscript. LW, WC, JZ, YY and LG gave final approval of the version to be published. All authors read and approved the manuscript and agree to be accountable for all aspects of the research in ensuring that the accuracy or integrity of any part of the work are appropriately investigated and resolved. All authors read and approved the final manuscript.

\section{Ethics approval and consent to participate}

Prior to the start of the study, ethical review approval was obtained and the subject's written informed consent was obtained. The study was approved by the Ethics Committee of the Stomatology Hospital of Guangzhou Medical University (no. KY2017015, Guangzhou, China), and written consent was acquired from the patients.

\section{Patient consent for publication}

Not applicable.

\section{Competing interests}

The authors declare that they have no competing interests.

\section{References}

1. Warnakulasuriya S: Global epidemiology of oral and oropharyngeal cancer. Oral Oncol 45: 309-316, 2009.

2. Ferlay J, Soerjomataram I, Dikshit R, Eser S, Mathers C, Rebelo M, Parkin DM, Forman D and Bray F: Cancer incidence and mortality worldwide: Sources, methods and major patterns in GLOBOCAN 2012. Int J Cancer 136: E359-E386, 2015.

3. Wu BH, Xiong XP, Jia J and Zhang WF: Micrornas: New actors in the oral cancer scene. Oral Oncol 47: 314-319, 2011.

4. Murugan AK, Munirajan AK and Alzahrani AS: MicroRNAs: Modulators of the ras oncogenes in oral cancer. J Cell Physiol 231: 1424-1431, 2016.

5. Chawla JP, Iyer N, Soodan KS, Sharma A, Khurana SK and Priyadarshni P: Role of miRNA in cancer diagnosis, prognosis, therapy and regulation of its expression by Epstein-Barr virus and human papillomaviruses: With special reference to oral cancer. Oral Oncol 51: 731-737, 2015.

6. Kozomara A and Griffiths-Jones S: miRBase: Annotating high confidence microRNAs using deep sequencing data. Nucleic Acids Res 42: D68-D73, 2014.

7. Shah MY and Calin GA: MicroRNAs as therapeutic targets in human cancers. Wiley Interdiscip Rev RNA 5: 537-548, 2014.

8. Mirnezamia AH, Pickard K, Zhang L, Primrose JN and Packham G: MicroRNAs: Key players in carcinogenesis and novel therapeutic targets. Eur J Surg Oncol 35: 339-347, 2009.

9. Shah MY, Ferrajoli A, Sood AK, Lopezberestein G and Calin GA: microRNA therapeutics in cancer-an emerging concept. Ebiomedicine 12: 34-42, 2016.

10. Chou J, Shahi P and Werb Z: microRNA-mediated regulation of the tumor microenvironment. Cell Cycle 12: 3262-3271, 2013.
11. Esposito CL, Cerchia L, Catuogno S, Vita GD, Dassie JP, Santamaria G, Swiderski P, Condorelli G, Giangrande PH and de Franciscis V: Multifunctional aptamer-miRNA conjugates for targeted cancer therapy. Mol Ther 22: 1151-1163, 2014.

12. Bi M, Chen W, Yu H, Wang J, Ding F, Tang DJ and Tang C: miR-543 is up-regulated in gefitinib-resistant non-small cell lung cancer and promotes cell proliferation and invasion via phosphatase and tensin homolog. Biochem Biophys Res Commun 480: 369-374, 2016.

13. Li J, Dong G, Wang B, Gao W and Yang Q: miR-543 promotes gastric cancer cell proliferation by targeting SIRT1. Biochem Biophys Res Commun 469: 15-21, 2016.

14. Yu L, Zhou L, Cheng Y, Sun L, Fan J, Liang J, Guo M, Liu N and Zhu L: MicroRNA-543 acts as an oncogene by targeting PAQR3 in hepatocellular carcinoma. Am J Cancer Res 4: 897-906, 2014.

15. Chen P, Xu W, Luo Y, Zhang Y, He Y, Yang S and Yuan Z: MicroRNA 543 suppresses breast cancer cell proliferation, blocks cell cycle and induces cell apoptosis via direct targeting of ERK/MAPK. Onco Targets Ther 10: 1423-1431, 2017.

16. Sun J, Zhou J, Dong M and Sheng W: Dysregulation of MicroRNA-543 expression in colorectal cancer promotes tumor migration and invasion. Mol Carcinog 56: 250-257, 2017.

17. Song N, Liu H, Ma X and Zhang S: Placental growth factor promotes metastases of ovarian cancer through MiR-543-regulated MMP7. Cell Physiol Biochem 37: 1104-1112, 2015.

18. Mbatchi LC, Gassiot M, Pourquier P, Goberna A, Mahammedi H, Mourey L, Joly F, Lumbroso S, Evrard A and Houede N: Association of NR1I2, CYP3A5 and ABCB1 genetic polymorphisms with variability of temsirolimus pharmacokinetics and toxicity in patients with metastatic bladder cancer. Cancer Chemother Pharmacol 80: 653-659, 2017.

19. Wahlang B, Falkner KC, Cave MC and Prough RA: Role of cytochrome $\mathrm{P} 450$ monooxygenase in carcinogen and chemotherapeutic drug metabolism. Adv Pharmacol 74: 1-33, 2015.

20. Mitra R, Guo Z, Milani M, Mesaros C, Rodriguez M, Nguyen J, Luo X, Clarke D, Lamba J, Schuetz E, et al: CYP3A4 mediates growth of estrogen receptor-positive breast cancer cells in part by inducing nuclear translocation of phospho-Stat 3 through biosynthesis of $( \pm)-14,15$-epoxyeicosatrienoic acid (EET). J Biol Chem 286: 17543-17559, 2011.

21. Fleming I: The cytochrome P450 pathway in angiogenesis and endothelial cell biology. Cancer Metastasis Rev 30: 541-555, 2011.

22. Jiang F, Chen L, Yang YC, Wang XM, Wang RY, Li L, Wen W, Chang YX, Chen CY, Tang J, et al: Cyp3a5 functions as a tumor suppressor in hepatocellular carcinoma by regulating mTORC2/Akt signaling. Cancer Res 75: 1470-1481, 2015.

23. Tanasubsinn P, Aung WPP, Pata S, Laopajon W, Makeudom A, Sastraruji T, Kasinrerk W and Krisanaprakornkit S: Overexpression of ADAM9 in oral squamous cell carcinoma. Oncol Lett 15: 495-502, 2018.

24. Li P, Wei X, Guan Y, Chen Q, Zhao T, Sun C and Wei L: MicroRNA-1 regulates chondrocyte phenotype by repressing histone deacetylase 4 during growth plate development. FASEB J 28: 3930-3941, 2014.

25. Livak KJ and Schmittgen TD: MAnalysis of relative gene expression data using real-time quantitative PCR and the 2(-Delta Delta C(T) method. Methods 25: 402-408, 2001.

26. Liu F, Lou K, Zhao X, Zhang J, Chen W, Qian Y, Zhao Y, Zhu Y and Zhang Y: miR-214 regulates papillary thyroid carcinoma cell proliferation and metastasis by targeting PSMD10. Int J Mol Med 42: 3027-3036, 2018.

27. Chandrashekar DS, Bashel B, Balasubramanya SAH, Creighton CJ, Poncerodriguez I, Chakravarthi BVSK and Varambally S: Ualcan: A portal for facilitating tumor subgroup gene expression and survival analyses. Neoplasia 19: 649-658, 2017.

28. Anaya J: OncoLnc: Linking TCGA survival data to mRNAs, miRNAs, and lncRNAs. PeerJ Comput Sci 2: e67, 2016.

29. Zhang GJ, Li JS, Zhou H, Xiao HX, Li Y and Zhou T: MicroRNA-106b promotes colorectal cancer cell migration and invasion by directly targeting DLC1. J Exp Clin Cancer Res 34: 73, 2015.

30. Liu HN, Qie P, Yang G and Song YB: miR-181b inhibits chemoresistance in cisplatin-resistant $\mathrm{H} 446$ small cell lung cancer cells by targeting Bcl-2. Arch Med Sci 14: 745-751, 2018.

31. Clément T, Salone V and Rederstorff M: Dual luciferase gene reporter assays to study miRNA function. Methods Mol Biol 1296: 187-198, 2015. 
32. Yang Y,Huang G,Zhou Z, Fewell JG and Kleinerman ES: miR-20a regulates Fas expression in osteosarcoma cells by modulating Fas promoter activity and can be therapeutically targeted to inhibit lung metastases. Mol Cancer Ther 17: 130-139, 2018.

33. Pink RC, Samuel P, Massa D, Caley DP, Brooks SA and Carter DR: The passenger strand, miR-21-3p, plays a role in mediating cisplatin resistance in ovarian cancer cells. Gynecol Oncol 137: 143-151, 2015.

34. de Vicente JC, Rodríguez-Santamarta T, Rosado P, Peña I and de Villalaín L: Survival after free flap reconstruction in patients with advanced oral squamous cell carcinoma. J Oral Maxillofac Surg 70: 453-459, 2012.

35. Garzon R, Calin GA and Croce CM: MicroRNAs in cancer. Annu Rev Med 60: 167-179, 2009.

36. Gorenchtein M, Poh CF, Saini R and Garnis C: MicroRNAs in an oral cancer context-from basic biology to clinical utility. J Dent Res 91: 440-446, 2012.

37. Li L and Ma HQ: MicroRNA-216a inhibits the growth and metastasis of oral squamous cell carcinoma by targeting eukaryotic translation initiation factor $4 \mathrm{~b}$. Mol Med Rep 12: 3156-3162, 2015.

38. Kawakita A, Yanamoto S, Yamada SI, Naruse T, Takahashi H, Kawasaki G and Umeda M: MicroRNA-21 promotes oral cancer invasion via the Wnt/ $\beta$-catenin pathway by targeting DKK2. Pathol Oncol Res 20: 253-261, 2014.

39. Peng SC, Liao CT, Peng CH, Cheng AJ, Chen SJ, Huang CG, Hsieh WP and Yen TC: MicroRNAs MiR-218, MiR-125b, and Let-7g predict prognosis in patients with oral cavity squamous cell carcinoma. PLoS One 9: e102403, 2014.

40. Min A, Zhu C, Peng S, Rajthala S, Costea DE and Sapkota D: MicroRNAs as important players and biomarkers in oral carcinogenesis. Biomed Res Int 2015: 186904, 2015.

41. Tsai SC, Huang SF, Chiang JH, Chen YF, Huang CC, Tsai MH, Tsai FJ, Kao MC and Yang JS: The differential regulation of microRNAs is associated with oral cancer. Oncol Rep 38 1613-1620, 2017.

42. Farooqi AA, Shu CW, Huang HW, Wang HR, Chang YT, Fayyaz S, Yuan SF, Tang JY and Chang HW: TRAIL, Wnt, sonic hedgehog, TGF $\beta$, and miRNA signalings are potential targets for oral cancer therapy. Int J Mol Sci 18: pii: E1523, 2017.

43. Skalsky RL and Cullen BR: Reduced expression of brain-enriched microRNAs in glioblastomas permits targeted regulation of a cell death gene. PLoS One 6: e24248, 2011.

44. Zhai F, Cao C, Zhang L and Zhang J: miR-543 promotes colorectal cancer proliferation and metastasis by targeting KLF4 Oncotarget 8: 59246-59256, 2017.
45. Xu L, Yu J, Wang Z, Zhu Q, Wang W and Lan Q: miR-543 functions as a tumor suppressor in glioma in vitro and in vivo. Oncol Rep 38: 725-734, 2017

46. Fan C,Lin Y,Mao Y,Huang Z, Liu AY, Ma H, Yu D, Maitikabili A, Xiao H, Zhang C, et al: MicroRNA-543 suppresses colorectal cancer growth and metastasis by targeting KRAS, MTA1 and HMGA2. Oncotarget 7: 21825-21839, 2016.

47. Zhang H, Guo X, Xing F, Wang T, Hu Z, Que X, Tian Q, Zhu T, Guo G, Huang W and Li X: MiRNA-543 promotes osteosarcoma cell proliferation and glycolysis by partially suppressing PRMT9 and stabilizing HIF-1 $\alpha$ protein. Oncotarget 8: 2342-2355, 2017.

48. Du Y, Liu XH, Zhu HC, Wang L, Ning JZ and Xiao CC: MiR-543 promotes proliferation and epithelial-mesenchymal transition in prostate cancer via targeting RKIP. Cell Physiol Biochem 41: 1135-1146, 2017

49. Wacher VJ, Wu CY and Benet LZ: Overlapping substrate specificities and tissue distribution of cytochrome P450 3A and P-glycoprotein: Implications for drug delivery and activity in cancer chemotherapy. Mol Carcinog 13: 129-134, 1995.

50. Lamba JK, Lin YS, Schuetz EG and Thummel KE: Genetic contribution to variable human CYP3A-mediated metabolism. Adv Drug Deliv Rev 54: 1271-1294, 2002.

51. Wojnowski L: Genetics of the variable expression of CYP3A in humans. Ther Drug Monit 26: 192-199, 2004.

52. Picard N, Rouguiegmalki K, Kamar N, Rostaing L and Marquet P: CYP3A5 genotype does not influence everolimus in vitro metabolism and clinical pharmacokinetics in renal transplant recipients. Transplantation 91: 652-656, 2011.

53. Zayed BEM and Mehaney D: The effect of CYP3A5 polymorphism on cyclosporine plasma level in Egyptian rena transplant recipients. Comp Clin Pathol 23: 1-5, 2014.

54. Islam MS, Mostofa AG, Ahmed MU, Bin Sayeed MS, Hassan MR and Hasnat A: Association of CYP3A4, CYP3A5 polymorphisms with lung cancer risk in Bangladeshi population. Tumor Biol 35 1671-1678, 2014

55. Ma LM, Liu HC, Ruan LH and Feng YM: CYP3A5 * 3 genetic polymorphism is associated with childhood acute lymphoblastic leukemia risk: A meta-analysis. Biomed J 38: 428-432, 2015.

56. Dhaini HR, Thomas DG, Giordano TJ, Johnson TD Biermann JS, Leu K,Hollenberg PF and Baker LH: Cytochrome P450 CYP3A4/5 expression as a biomarker of outcome in osteosarcoma. J Clin Oncol 21: 2481-2485, 2003.

This work is licensed under a Creative Commons Attribution-NonCommercial-NoDerivatives 4.0 International (CC BY-NC-ND 4.0) License. 